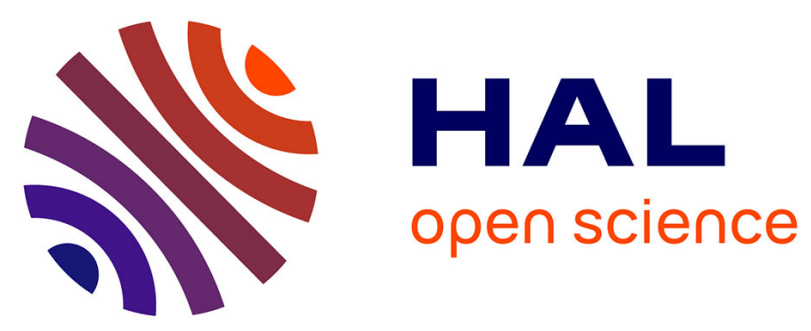

\title{
Short crack propagation from cracked non-metallic inclusions in a Ni-based polycrystalline superalloy
}

Damien Texier, Jean-Charles Stinville, Mclean Echlin, Stéphane Pierret, Patrick Villechaise, Tresa Pollock, Jonathan Cormier

\section{To cite this version:}

Damien Texier, Jean-Charles Stinville, Mclean Echlin, Stéphane Pierret, Patrick Villechaise, et al.. Short crack propagation from cracked non-metallic inclusions in a Ni-based polycrystalline superalloy. Acta Materialia, 2019, 165, pp.241-258. 10.1016/j.actamat.2018.11.051 . hal-01943918

\section{HAL Id: hal-01943918 https://imt-mines-albi.hal.science/hal-01943918}

Submitted on 4 Dec 2018

HAL is a multi-disciplinary open access archive for the deposit and dissemination of scientific research documents, whether they are published or not. The documents may come from teaching and research institutions in France or abroad, or from public or private research centers.
L'archive ouverte pluridisciplinaire HAL, est destinée au dépôt et à la diffusion de documents scientifiques de niveau recherche, publiés ou non, émanant des établissements d'enseignement et de recherche français ou étrangers, des laboratoires publics ou privés. 


\title{
Short crack propagation from cracked non-metallic inclusions in a $\mathrm{Ni}$ - based polycrystalline superalloy
}

\author{
Damien Texier a, b, c, *, Jean-Charles Stinville ${ }^{\text {b }}$, McLean P. Echlin ${ }^{\mathrm{b}}$, Stéphane Pierret ${ }^{\mathrm{d}}$, \\ Patrick Villechaise ${ }^{a}$, Tresa M. Pollock ${ }^{b}$, Jonathan Cormier ${ }^{\text {a, }}{ }^{* *}$ \\ a Institut Pprime, UPR CNRS 3346, ISAE-ENSMA, Téléport 2, 1 avenue Clément Ader, BP 40109, Futuroscope-Chasseneuil Cedex, 86961, France \\ ${ }^{b}$ Materials Department, University of California Santa Barbara, Santa Barbara, CA, 93106, United States \\ ' Institut Clément Ader (ICA), Université de Toulouse, CNRS, IMT Mines Albi, INSA, ISAE-SUPAERO, UPS, Campus Jarlard, F-81013, Albi, France \\ d SAFRAN Aircraft Engines, Site de Villaroche, Rond-Point René Ravaud, Moissy-Cramayel, 77550, France
}

\begin{abstract}
A B S T R A C T
Fatigue cracks initiating from surface and sub-surface non-metallic inclusions (NMIs) have recently been demonstrated to be a necessary but not sufficient explanation for atypically short low-cycle fatigue life in Inconel 718 alloy at intermediate temperature. Therefore, the early stages of short crack propagation from surface NMIs were investigated in a crystallographic and two-dimensional versus threedimensional morphological manner after room temperature low cycle fatigue (LCF) testing. In the present investigation, NMIs were purposely pre-cracked using different techniques to suppress the natural crack initiation period and thus the incubation period prior to the early stages of crack propagation. Under such fatigue testing conditions, different mechanisms of crack transmission from pre-cracked NMIs were identified: (i) no propagation, (ii) NMI/adjacent metallic grain interfacial debonding, (iii) transgranular crack propagation within the adjacent metallic grain. Focused-ion-beam cross-section observations of numerous fatigue tested NMIs aimed to define a morphological criterion for nonpropagating NMIs. Large cracked NMIs at the surface $(2 c)$ with limited extension into the depth $(a)$ did not propagate under such fatigue conditions for $2 c / a$ ratio higher than 3 . Furthermore, specific crystallographic relationships between NMIs and the adjacent metallic grain explained different crack propagation configurations from pre-cracked NMIs, i.e. interfacial debonding and transgranular crack propagation involving single or multiple-slip activity.
\end{abstract}

\author{
Keywords: \\ Low cycle fatigue \\ Superalloy 718DA \\ Short crack propagation \\ Non-metallic inclusions \\ Focus-ion-beam cross-section (FIB-cross \\ section)
}

\section{Introduction}

Inconel 718 (IN718) alloy is a wrought nickel-base superalloy commonly used for structural components operating at temperatures up to $650^{\circ} \mathrm{C}$ [1]. IN718 alloy exhibits high strength and suitable low cycle fatigue (LCF) resistance, critical for rotating massive components for aeronautic applications, such as turbine disks [2,3]. For such critical applications, fine grain microstructures in the range of $5-15 \mu \mathrm{m}$ (ASTM 12 to 9 ) are expected to maximize fatigue

\footnotetext{
* Corresponding author. Institut Clément Ader (ICA), Université de Toulouse, CNRS, IMT Mines Albi, INSA, ISAE-SUPAERO, UPS, Campus Jarlard, F-81013, Albi, France.

** Corresponding author. Institut Pprime, UPR CNRS 3346, ISAE-ENSMA, Téléport 2,1 avenue Clément Ader, BP 40109, Futuroscope-Chasseneuil Cedex, 86961, France. E-mail addresses: damien.texier@mines-albi.fr (D. Texier), jonathan.cormier@ ensma.fr (J. Cormier).
}

performance. To assess such performance in this range of grain sizes, "direct aged" forging/post heat treatment route of wrought IN718 alloys has been adopted [4,5]. Standard precipitation treatments were directly applied after the last forging stages at temperatures close to the $\delta$-phase solvus, without any solution heat treatment. This process route subsequently confers finer grain size and higher amount of the strengthening $\gamma$ "-phase microstructures than standard solution treated variants. This IN718 metallurgical variant is called the direct-aged version of the IN718 alloy (IN718DA).

However, grain size refinement and high fraction of strengthening precipitates might have some design limitations since coarser brittle microstructural features, i.e. carbides ( $\mathrm{NbC}$ ), nitrides (TiN) or carbonitrides ( $\mathrm{NbC}-\mathrm{TiN}$ ) referred to here as non-metallic inclusions (NMIs), appear to be crack initiation sensitive features under cyclic stresses [6-14]. Depending on the operating temperature, NMIs have been reported to fail (i) by NMI cracking in a 
brittle manner due to the application of the external loading as low as $60 \%$ of the 0.2 pct.-offset yield strength $[6,7,9,10,13,15,16]$, (ii) by $\mathrm{NMI} /$ metallic matrix debonding due to cyclic stresses [7,16], (iii) by through-metallic-matrix-oxide eruption cracking due to selective fast growth oxidization at high temperature [17-20], or by (iv) machining and surface finishing operations [8,21-23]. A recent study reported that the combination of fine grain microstructure $(15 \mu \mathrm{m}$ mean diameter and finer grain size microstructure, i.e. ASTM 9 and higher values) and a content of $\delta$-phase lower than $3.0 \%$ (inversely a high $\gamma$ "-precipitates content) can occasionally lead to a ten-to-hundred-fold reduction in fatigue life at intermediate temperature [6].

The current fatigue life prediction approaches for failure of critical components are based on the probability of the worst-case occurrence [24]. Such lifespan variability considerably restricts a design efficient usage of the IN718DA alloy for critical structural components despite its overall improvement of the fatigue performance. Therefore, a mechanistic understanding of the origin of these non-systematic low fatigue life failures is required. Specifically a criterion for crack propagation from NMIs is needed. NMIs have been shown to be most detrimental in the low temperature range at high stress level, where the brittle behavior of inclusions and strain localization within the surrounding metallic grains is likely maximal $[8-11,25,26]$. Recent studies also highlight potential danger from (sub)-surface NMIs in the low plastic deformation regime leading to very short fatigue life.

In this present study, early life failures from NMIs in IN718DA alloy at room temperature have been examined. Since the principal crack systematically initiated from surface/sub-surface NMIs for abnormally short fatigue life, this study has focused on development of morphological and crystallographic criteria via study of multiple cracked NMIs and their neighboring grains. Due to the stochastic incubation time for crack initiation within NMIs, a fraction of NMIs were "naturally" cracked prior to fatigue testing. Two different ways to introduce prior damage were investigated. The early stages of short crack propagation from these pre-damaged inclusions was followed at different life fractions at room temperature via electron back-scattered diffraction (EBSD) characterization. Focused-ion-beam cross-section (FIB-CS) characterizations were employed to evaluate three-dimensional shape factors influencing the crack growth capability from surface NMIs.

\section{Material and experimental conditions}

\subsection{Materials}

Three experimental forged pancakes were produced in the present study in order to obtain three different IN718DA microstructures from the same initial ingot. The three pancakes subsequently have a similar non-metallic-inclusion (NMI) microstructure in terms of size, morphology, fraction and distribution from pancake to pancake. The initial ingot was a commercially vacuum induction melted ingot with the following nominal composition (in weight \%) Ni-0.56Al-18.0Cr-17.3Fe-0.14Co-5.4( $\mathrm{Nb}+\mathrm{Ta})-0.023 \mathrm{C}$. The height and the diameter of the initial cylindrical ingot were $250 \mathrm{~mm}$ and $100 \mathrm{~mm}$, respectively. The goal of the processing/ microstructure design was to produce three slightly different microstructures of IN718DA matching with the metallurgical specifications of abnormally short fatigue life specimens defined in a previous study (Ref. [6]): fine grain microstructure $(15 \mu \mathrm{m}$ mean diameter and finer grain size microstructure/ASTM 9 to 12) and content of $\delta$-phase lower than $3.2 \%$. The different experimental pancakes were forged by hot-die forging by SAFRAN Aircraft Engines, and are denoted PAN-X. Prior to forging, ingots were heated up to $985^{\circ} \mathrm{C}$ for $3 \mathrm{~h}$, i.e. up to a temperature slightly lower than the $\delta$-phase solvus temperature. The main difference in the forging parameters for the production of the three experimental metallurgical states was the upsetting forging rate, as shown in Table 1. Pancakes were water quenched after forging, then directly aged with a standard aging treatment. The standard aging treatment consists in a $8 \mathrm{~h}$ dwell at $720^{\circ} \mathrm{C}$, followed by a controlled cooling $\left(0.83^{\circ} \mathrm{C} \cdot \mathrm{min}^{-1}\right)$ down to $620^{\circ} \mathrm{C}$. A second $8 \mathrm{~h}$ dwell was performed at this latter temperature, then air cooled to room temperature.

\subsection{Micromechanical specimens extraction and preparation}

Micromechanical specimens were extracted with electrodischarge machining (EDM) from a homogeneous region of the pancakes in terms of microstructure, identical to the one investigated in Ref. [7]. The loading direction of the specimen was parallel to the radial direction of the pancakes. The specimen geometry consists in flat pin-loaded specimen with a gage length of $10 \mathrm{~mm}$, a gage width of $2 \mathrm{~mm}$, a total length of $32 \mathrm{~mm}$, a head width of $10 \mathrm{~mm}$, and a thickness of $1 \mathrm{~mm}$ (see e.g. Ref. [6] for the drawing of the micromechanical specimen). Micromechanical specimens were mechanically ground then polished down to a $1 \mu \mathrm{m}$ diamond particle finishing (faces and edges with a particular attention in the radius between the gage zone and the head). The gage zone of the specimens was finally electrochemically polished with a $10 \%$ vol. perchloric acid diluted in methanol solution under $45 \mathrm{~V}$ at $4{ }^{\circ} \mathrm{C}$. This final step aimed to reduce superficial residual stresses from mechanical polishing and to prepare the specimen surface for further EBSD characterizations.

\subsection{Tensile and interrupted fatigue testing at room temperature}

Tensile tests were performed at room temperature on an Instron $^{\mathrm{TM}} 1362$ electromechanical fatigue machine under displacement control with a strain rate of $10^{-4} \mathrm{~s}^{-1}$. The dimensional variations of the specimen were continuously recorded with both the displacement of grips and an extensometer sampling the specimen gage length. A summary of the $0.2 \%$ offset yield strength of the three pancakes is reported in Table 2 .

Low cycle fatigue (LCF) fatigue tests were performed at room temperature under load control, with a positive stress ratio $R_{\sigma}=0.05$ using a $1 \mathrm{~Hz}$ triangle waveform. The maximum stress was chosen to be equal to the stress measured at a total deformation of $0.67 \%$ for each microstructure $\left(\sigma_{\max }\left(25^{\circ} \mathrm{C}\right) \approx 1270 \mathrm{MPa}\right)$. Interrupted LCF tests were conducted to investigate the early stage of crack propagation. Fatigue tests were interrupted after 10, 100, 1,000 and 5,000 and 10,000 cycles. Fifteen to twenty five cracked NMIs were observed and tracked per specimen. Different cases of NMIs were investigated, i.e. isolated carbides, nitrides or carbonitrides or cluster of those NMIs.

\subsection{Damage introduction prior to LCF experiments}

In a previous study, crack initiation from surface/sub-surface NMIs was reported to be a necessary condition for abnormally short fatigue life (Ref. [6]). The goal of cracking NMIs prior to LCF testing was to investigate the early stages of natural crack propagation from NMIs. Pre-cracking multiple NMIs aimed to investigate multiple initiation site configurations on the same sample, i.e. isolated carbides, nitrides or carbonitrides or clusters of those NMIs. This aspect is of major interest since crack initiation from NMIs did not necessarily lead to abnormally short fatigue life (Ref. [6]). Two methods were developed to crack a fraction of NMIs prior to LCF tests, i.e. interrupted tensile tests in the plastic domain $\left(\varepsilon_{\text {plastic }}=0.75 \% \rightarrow \sigma_{\max } \approx 1350-1395 \mathrm{MPa}\right)$ and microindentations within NMIs under uniaxial loading in the elastic 
Table 1

Forging parameters for the production of the three experimental microstructures.

\begin{tabular}{|c|c|c|c|}
\hline & PAN-1\&2 & PAN-3\&4 & PAN-5\&6 \\
\hline Forging temperature $\left({ }^{\circ} \mathrm{C}\right)$ & 985 & 985 & 985 \\
\hline High temperature dwell duration prior to forging $(h)$ & 3 & 3 & 3 \\
\hline Upsetting forging rate $\left(\mathrm{mm} \cdot \mathrm{s}^{-1}\right)$ & 5 & 15 & 3 \\
\hline Cooling route & Static water quench & Static water quench & Agitated water quench \\
\hline
\end{tabular}

Table 2

Summary of different microstructural parameters and macroscopic mechanical behavior of the three experimental pancakes.

\begin{tabular}{llll}
\hline & PAN1\&2 & PAN3\&4 & PAN5\&6 \\
\hline Average grain size $(\mu \mathrm{m})$ & 8.7 & 7.5 & 11.6 \\
Maximum grain diameter $(\mu \mathrm{m})$ & 23.5 & 23.5 & 28.5 \\
- -phase content $(\%$, image proc.) & $1.5 \pm 0.2$ & $2.0 \pm 0.3$ & $0.8 \pm 0.2$ \\
Yield Stress @RT (MPa) & $1323 \pm 6$ & $1332 \pm 4$ & $1295 \pm 5$ \\
\hline
\end{tabular}

domain $\left(\varepsilon_{\text {total }}=0.4 \% \rightarrow \sigma \approx 820 \mathrm{MPa}+200 \mathrm{mN}\right.$ microhardness load locally), this latter technique aiming to create "natural" cracks without affecting the surrounding matrix. As reported in a preliminary study (Ref. [6]), approximately thirty percent of NMIs are cracked after interrupted tensile test at $0.75 \%$ plastic strain. For predamage introduction via micro-indentation, around 20 to 30 inclusions were indented and $80 \%$ of them cracked. Only coarse NMIs $(D>10 \mu \mathrm{m})$ were micro-indented for technical reasons and feasibilities. Typical examples of pre-cracked NMIs in tension in the plastic domain or via microindentation were detailed in Ref. [7]. Interrupted tensile tests reveal (i) slightly open cracked NMIs without severe plastic deformation in the surrounding metallic matrix, (ii) open cracked NMIs with intense plasticity in the vicinity of the crack tip involving the activity of at least two slip systems, (iii) intense slip activity in the surrounding grains of a cracked NMI. Typical examples of cracked NMIs via micro-indentations under loading within the macroscopic elastic regime were: (i) cracked NMIs whose crack split entirely the inclusion, (ii) partially cracked NMIs, (iii) cracked NMIs due to the tensile loading, i.e. without indent. NMIs failed in a brittle manner for the two ways to predamage them. The crack path within NMIs was complex, generally along several different crystallographic planes. Plane trace analyses at the surface of the cracked NMIs via EBSD characterizations identified two different crystallographic planes for the cleavage of NMIs, i.e. $\{001\}$ and $\{011\}$ planes with similar probabilities of failure from $\{001\}$ or $\{011\}$ planes. FIB cross-section observations were also conducted on a pre-cracked carbide in tension depicting a slight deviation of the crack path at the surface (green and red arrows in Fig. 1). Cross-sectional observations revealed the combination of two crystallographic cleavage planes, i.e. $\{011\}$ and $\{001\}$ crystallographic plane depicted as green and red arrows in Fig. 1, respectively. The two planes present a low-angle-surfacetrace misorientation but a high-twist-angle-cross-section trace misorientation. Therefore, the crack path within a single crystal orientation NMI was relatively complex, especially from microindentation induced pre-cracks.

\subsection{Microscopy observations and EBSD analyses}

A FEI/Philips XL30 and a Jeol 6400 scanning electron microscope were used in secondary electron mode and a back-scattered electron mode in the $15-20 \mathrm{kV}$ range for microstructural, crack propagation and fractographic observations. A Zeiss Axio Imager Vario optical microscope was used in a differential interference contrast mode at high magnification for the evaluation of short crack propagation from several pre-cracked NMIs at the different fatigue interruptions. During the optical observations, the fatigued specimens were in-situ loaded with a DEBEN microtensile apparatus up to $425 \mathrm{MPa}$, i.e. one third of the maximal cyclic stress, in order to slightly open the small cracks and subsequently detect them. An image processing procedure based in image registration then image difference between the $\mathrm{N}$-cycle micrograph and the 0 -cycle micrograph aimed to better highlight the crack path using Fiji software [27]. FIB cross-sections were prepared with a FEI Helios FEG system (FIB-SEM). The region of interest (ROI) was first platinum-plated with an electron deposition (50 nm thin Pt-layer) not to alter the surface of the ROI then with an argon deposition ( $250 \mathrm{~nm}$ thick Pt-layer) to limit edge effects during the FIB crosssection procedure. EBSD scans were carried out with an OIM $^{\mathrm{TM}}$ software from EDAX acquisition setup equipped on a conventional SEM of JEOL 6100 type. $80 \times 150 \mu \mathrm{m}^{2}$ areas around all the NMIs studied after interrupted LCF tests were analyzed with a $0.2 \mu \mathrm{m}$ step hexagonal grid pattern. The EBSD analyses aimed to document both the effect of the orientation of the NMIs but also the neighborhood grains related to the macroscopic load application on the ease of short crack propagation. A large area $\left(280 \times 350 \mu \mathrm{m}^{2}\right)$ was analyzed for each pancake variant in order to characterize the grain microstructure. EBSD scans were conducted according to a regular hexagonal grid pattern with a scan step of $0.25 \mu \mathrm{m}$.

\section{Results}

\subsection{Microstructure of the different pancakes}

The microstructures of the three experimental pancakes were investigated by means of EBSD characterization in the TD-RD plane. Slight differences in terms of grain size were observed for the three pancakes, as depicted in Fig. 2 via the inverse pole figure (IPF) maps represented according to the radial direction of the pancake, i.e. the loading direction of LCF specimens. All the pancake variants possessed equiaxed microstructures with twinned grains. It is worth noting that higher upsetting forging rates lead to finer grain size microstructures $\left(D_{\text {mean }}^{P A N 3 \& 4}<D_{\text {mean }}^{\text {PAN1 } 22}<D_{\text {mean }}^{\text {PAN5\&6 }}\right)$ and higher content of $\delta$-phase $\left(f\left(\delta_{-} \text {phase }\right)_{\text {mean }}^{\text {PAN3 } 4}>f\left(\delta_{-} \text {phase }\right)_{\text {mean }}^{\text {PAN1\&2 }}>\right.$ $\left.f\left(\delta_{-} \text {phase }\right)_{\text {mean }}^{P A N 5 \&}\right)$. A summary of these microstructural characteristics is reported in Table 2. Since the three experimental pancakes were forged from the same input billet, the morphology and proportion of non-metallic inclusions should be constant for the different pancakes. Qualitative observations of hundreds of NMIs per experimental pancakes aimed to support this supposition. EBSD characterizations highlighted that no preferential crystallographic orientations was found for such forging conditions since the maximal texture index for ODF maps represented on IPF maps according to the loading direction is lower 1.7. In other words, the three experimental pancakes gather the microstructural conditions to favor abnormally low LCF life according to our previous study Ref. [6], but with slight microstructural variations. A more detailed characterization of the three experimental pancakes is reported in Ref. [7]. 

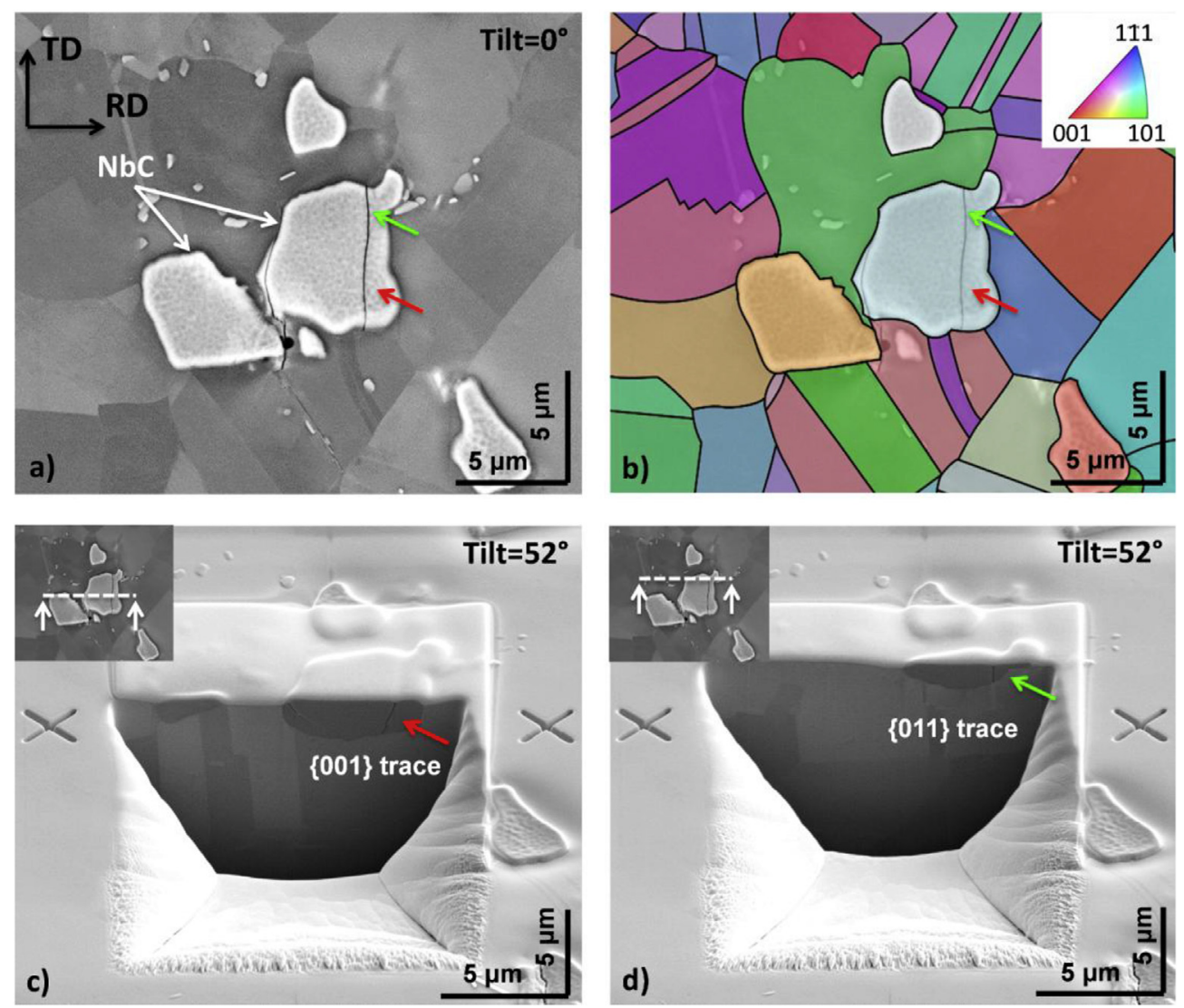

Fig. 1. FIB cross-section and EBSD characterization of a pre-cracked carbide (NbC) in tension involving the combination of $\{001\}$ and $\{011\}$ cleavage planes. a) Top view observation of the pre-cracked carbide prior to FIB machining. Green and red arrows highlight two different traces of plane along the crack path. b) EBSD map of the region of interest showing the single orientation within the pre-cracked NMIs. The EBSD map is represented as IPF maps according to the loading direction (horizontal). c) FIB-cross section observation of the bottom region of the pre-cracked carbide (red arrow in Fig. 1a). The crystallographic plane has been identified as \{001\} crystallographic plane. d) FIB-cross section observation of the top region of the pre-cracked carbide (green arrow in Fig. 1a). The crystallographic plane has been identified as \{011\} crystallographic plane. (For interpretation of the references to color in this figure legend, the reader is referred to the Web version of this article)

a)

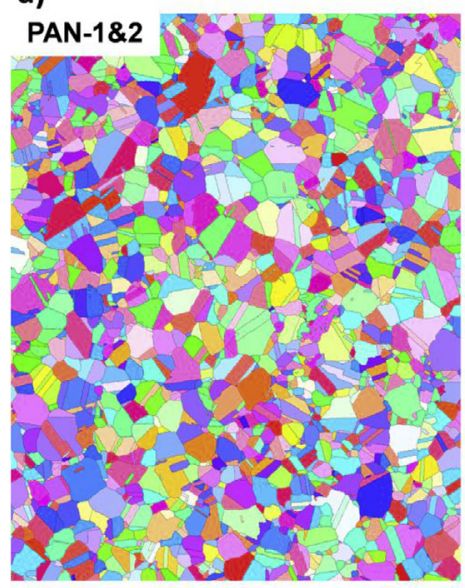

b)

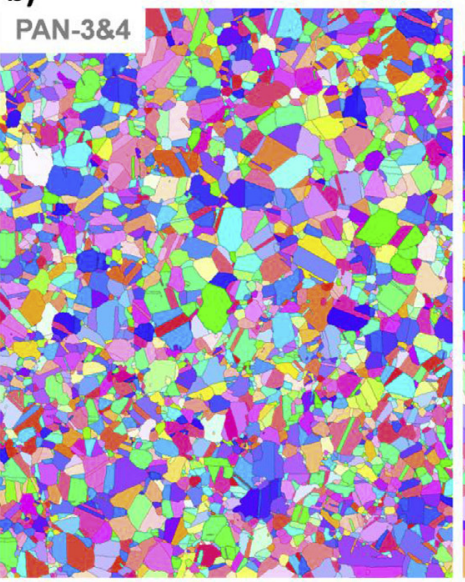

c)

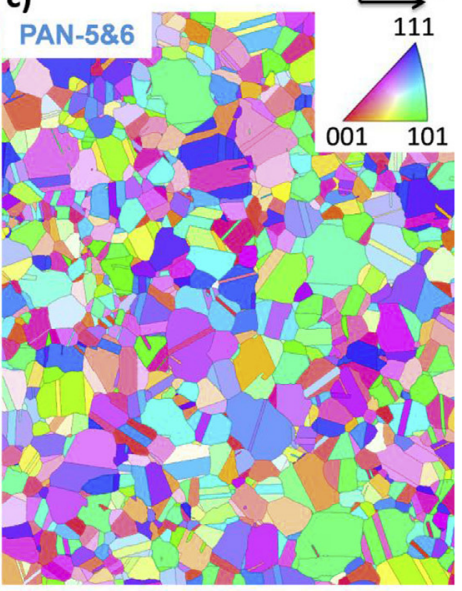

$50 \mu \mathrm{m}$

Fig. 2. Grain microstructure of the different microstructures represented as orientation maps according to the RD direction (loading direction): a) PAN-1\&2, b) PAN-3\&4, c) PAN$5 \& 6$. 
3.2. Investigation of the short crack propagation at room temperature

\subsubsection{Crack propagation from pre-damaged non-metallic inclusions}

Interrupted fatigue tests were performed at room temperature for the three experimental pancakes in order to investigate the initial crack propagation steps from NMIs. Prior to fatigue testing, SEM surface observations were conducted after pre-damaging conditions in order to identify and further follow pre-cracked NMIs after several cycles. Fifteen to twenty five cracked NMIs were observed per specimens for each fatigue interruption $(10,100$, 1,000, 5,000 and 10,000 cycles). Different cases of NMIs were investigated, i.e. isolated carbides, nitrides or carbonitrides or cluster of those NMIs. Fig. 3 illustrates the evolution of a crack propagating from a cluster of nitrides (TiN) at different fatigue life fractions (the loading direction is horizontal), the extent of the crack being highlighted by white arrows. The cluster of nitrides was pre-damaged via interrupted tensile test in the early plastic domain. As shown in the insert in Fig. 3a, only the upper nitride was cracked following the pre-damage introduction. No evidence of crack propagation was found after 1,000 cycles for this specific region of interest. At 5,000 cycles, the crack propagation through the second nitride and in the surrounding grains was clearly depicted in Fig. 3b. The crack propagation in the upper grains was not straightforward to observe via optical microscopy, but the aforementioned image processing procedure aimed to reveal it; this crack path in the upper grain was then confirmed when observing this region of interest after 10,000 cycles. The total crack length was about $21 \mu \mathrm{m}$. At 10,000 cycles (Fig. 3c), the crack propagated on both sides of the cluster of nitrides up to $69 \mu \mathrm{m}$. Higher magnification micrographs obtained via scanning electron microcopy in a back-scattered electron mode better highlighted the relatively complex crack path, involving different planes (Fig. 3d and e). Crystallographic analyses aimed to identify that the different planes correspond to $\{111\}$ slip planes, as shown in Fig. 4. At this stress level regime, crack grows via two activated planes in the vicinity of the pre-cracked nitride (lower magnified micrograph) but also further along the crack path (upper magnified micrograph).

Surface observations of the fatigued specimens after 10,000 cycles were conducted in order to evaluate the crack length distribution of the followed pre-cracked carbides for the two ways to introduce pre-damage for the three experimental pancake variants. Since the crack propagation in the metallic grains follow crystallographic slip planes, the crack length (C.L.) measurement was considered as the sum of the different $\{111\}$ trace segments of the activated slip planes along the crack path. The trace directions of the activated slip planes for each grain were obtained via EBSD characterization and the crack length within a grain correspond of the norm of the different activated $\{111\}$ vectors necessary connect the entrance and exit of the crack through the grain. Since similar crack propagation behaviors between pancakes, the crack length distribution was plotted in Fig. 5 regardless of the microstructure for the two ways to introduce pre-damage. An uncertainty of $2 \mu \mathrm{m}$ in crack length measurement is estimated for long cracks and less than $0.5 \mu \mathrm{m}$ uncertainty for cracks shorter than $5 \mu \mathrm{m}$. It was found that some pre-cracked NMIs stressed in tension propagate into the surrounding metallic matrix with a crack path as long as $133 \mu \mathrm{m}$, while some other NMI cracks did not propagate at all. Similar results were found for the materials pre-damaged by microindentation (maximum crack length of $49 \mu \mathrm{m}$ ). A non-negligible fraction of non-propagating pre-cracked inclusions were noticed ( $16 \pm 4 \%$ for the tensile pre-damage condition and $39 \pm 15 \%$ for the micro-indentation pre-damage condition) and a maximal fraction of cracks with length ranging from 5 to $10 \mu \mathrm{m}$, i.e. shorter than the average grain size diameter. On the whole, a difference in crack length distribution was observed in the two pre-damage approaches. Indeed, the overall crack length was found two times higher for the tensile pre-damage condition (black histogram in Fig. 5) compared to the micro-indentation pre-damage condition (gray histogram in Fig. 5) and the fraction of non-propagating precracked NMIs was also lower. The prior-tensile pre-damage, i.e. "overloading", thus favored short crack propagation in comparison with the micro-indentation pre-damage.

\subsubsection{Different crack path configurations}

For the hundred pre-cracked NMIs investigated, the crack propagation path from the NMIs into the surrounding metallic matrix was studied. Typical crack path configurations after 10,000 cycles at room temperature are depicted in Fig. 6 for the two methods of pre-damage. While the rate of short crack propagation varied with pre-damage method, there were similarities in crack path independent of the pre-damage technique, including: (i) few grain long cracks from isolated NMIs (Fig. 6a and e) or clusters of NMIs (Fig. 6b), (ii) large cracked NMIs often did not propagate into the surrounding grains (Fig. 6c), (iii) complex crack paths involving one or several slip systems (Fig. 3d and e), and (iv) NMI/metallic matrix debonding (Fig. 6d). For pre-damage introduction via microindentation, it was found that only a few NMIs cracked due to the application of the uniaxial stress (800 MPa), as depicted in Fig. 6e. Those NMI cracks were found to easily propagate for a maximum cyclic stress higher than the pre-damaging load level, i.e. $1270 \mathrm{MPa}$ for this study.

\subsubsection{Morphological considerations of initial pre-cracked NMIs on} the crack propagation capability: surface and cross-section observations

In order to evaluate the morphological effect of pre-cracked NMIs on the ease of crack propagation, the length of the cracks propagating in the metallic matrix was related to the initial crack length within the NMIs for all the microstructure variants and the pre-damage conditions (Fig. 7). Isolated NMIs (solid marker) were distinguished from clusters of NMIs observable from the surface (empty marker). Interestingly, clusters of NMIs were shown to favor crack propagation in the metallic matrix. As far as isolated NMIs are concerned, no relation was found between the size of the initial damage and the propagating crack length via surface observations. Indeed, the longest initial crack within NMIs for the tensile predamage condition (see e.g. crack length within cracked NMIs $>19.5 \mu \mathrm{m}$ in Fig. $7 \mathrm{a}$ ) did not propagate while the two smallest initial cracks within NMIs lead to cracks at the end of the tail of crack length distribution for isolated NMIs, i.e. 45 and $51 \mu \mathrm{m}$ crack length (see e.g. red arrows in Fig. 7a). Similar results were found for the pre-damage introduction by micro-indentation, as depicted in Fig. 7b.

Morphological investigations of cracked NMIs via surface observation did not provide conclusive correlations between the size of the initial defects (pre-cracked NMIs) and the crack length within the metallic matrix. However, it was found that clusters of NMIs have an amplifying action on the crack growth from NMIs. Therefore, cross-section observations via FIB machining of cracked NMIs were conducted in order to evaluate the contribution of the sub-surface microstructure in the vicinity of pre-cracked NMIs on the ease of crack propagation. Fig. 8 shows serial sectioning of a previously investigated cracked carbide (see e.g. Fig. 1). Top surface observations identified two cracks within the carbide; the one on the left propagating, the one on the right not propagating (Fig. 8). As shown in Fig. 1, different $\{011\}$ and $\{001\}$ cleavage planes were involved on the cracking of the NMIs. Moreover, additional FIB cross-sectioning identified sub-surface cracked carbides on the 
a) 1,000 cycles (RT)

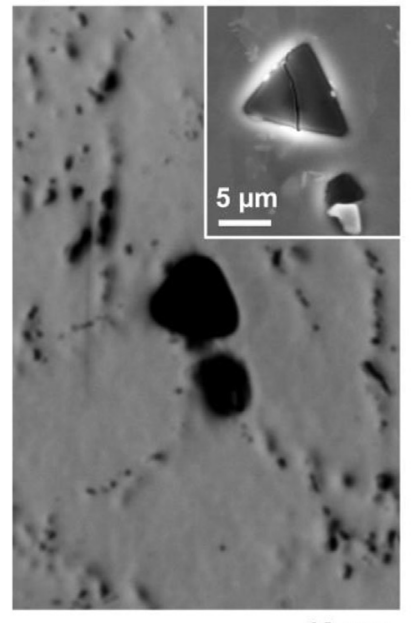

$10 \mu \mathrm{m}$ b) $\quad 5,000$ cycles (RT)

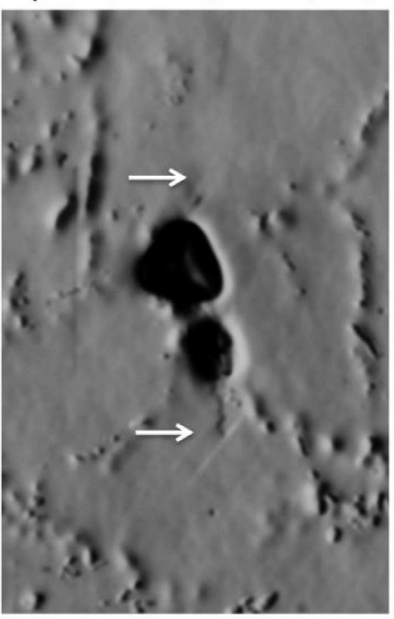

$10 \mu \mathrm{m}$ c) 10,000 cycles (RT)

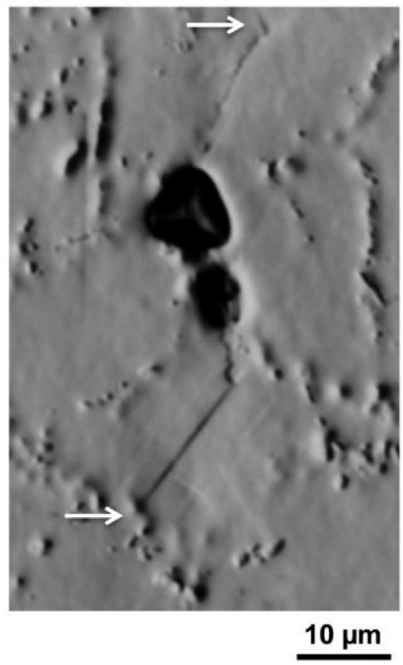

d)

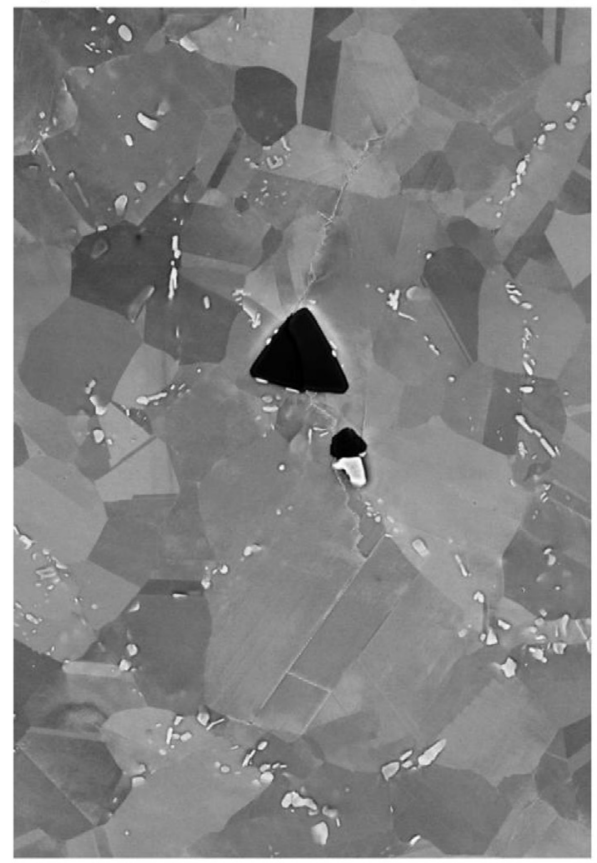

e)

10,000 cycles (RT)

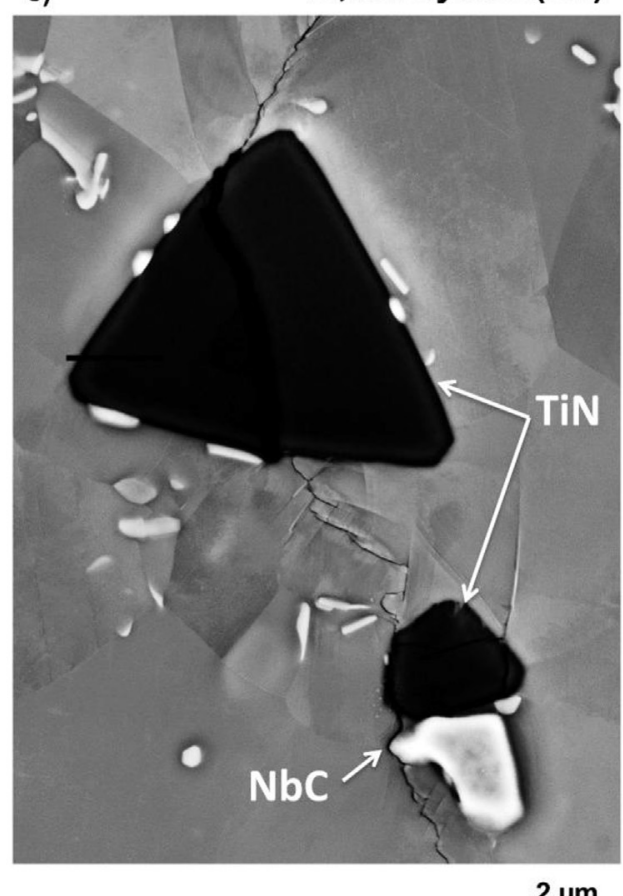

Fig. 3. Illustration of the evolution of a crack at different fatigue life: case of a cluster of nitrides (TiN) pre-damaged in tension and fatigue tested at room temperature up to 10,000 cycles. Optical observation of the crack at: a) 1,000 cycles. The insert micrograph corresponds to a SEM micrograph of the pre-cracked upper nitride due to pre-damage introduction. b) 5,000 cycles. The white arrow shows the progression of the crack. c) 10,000 cycles. d and e) Higher magnification micrographs obtained via SEM in a back-scattered electron mode after 10,000 cycles.

bottom left of the surface NMI, at a location where the crack was observed via surface observations (highlighted by white arrows in Fig. 8d and e). Interestingly, NMIs clustering in the volume also favored crack propagation. This NMIs cluster configuration was further denoted "sub-surface cluster of NMIs" in contrast to "surface cluster of NMIs", observable from surface observation.

As aforementioned, coarse pre-cracked surface NMIs do not necessarily lead to crack propagation (Fig. 7). Extreme crack configurations are depicted in Fig. 9, i.e. a small cracked surface carbides leading to crack propagation and a large cracked surface carbides not propagating. Interestingly, FIB-cross-sections aimed to highlight the inverse dimensional relationship in the volume. In other words, the small cracked surface carbide was found to extend relatively deep into the volume ( $10 \mu \mathrm{m}$ at the surface and $17 \mu \mathrm{m}$ in depth, as shown in Fig. 9a and b) and inversely, the coarse cracked surface carbide did not extend as far into the sub-surface (20 $\mu \mathrm{m}$ at the surface and $6 \mu \mathrm{m}$ in depth, as shown in Fig. 9c and d).

Surface and FIB cross-section observations of approximately 


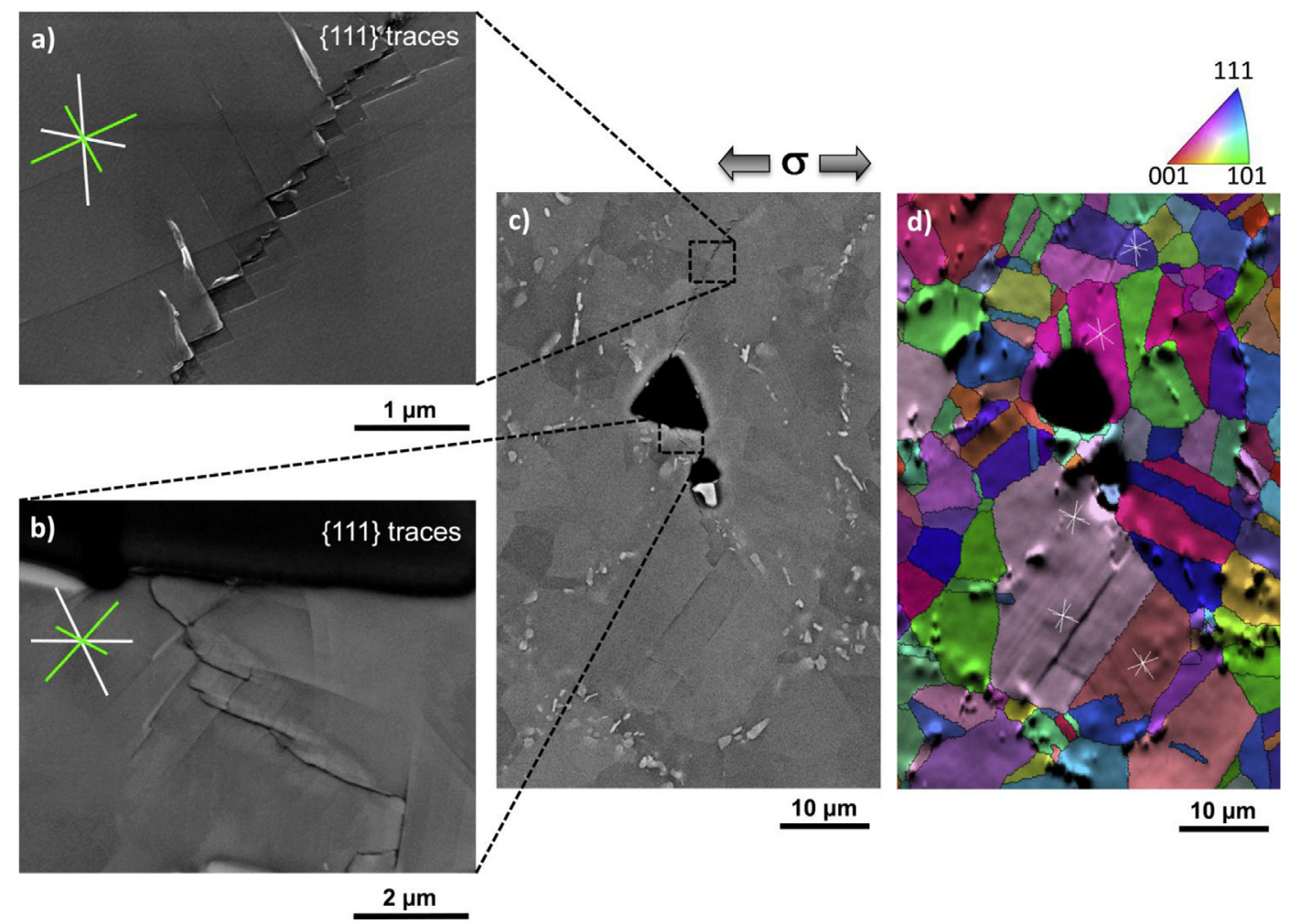

Fig. 4. EBSD analyses of a crack path highlighting the combination of $\{111\}$ slip planes to form the crack. All the $\{111\}$ trace planes are reported as white and green lines in the magnified micrographs, the green lines corresponding to the activated slip trace planes. (For interpretation of the references to color in this figure legend, the reader is referred to the Web version of this article)

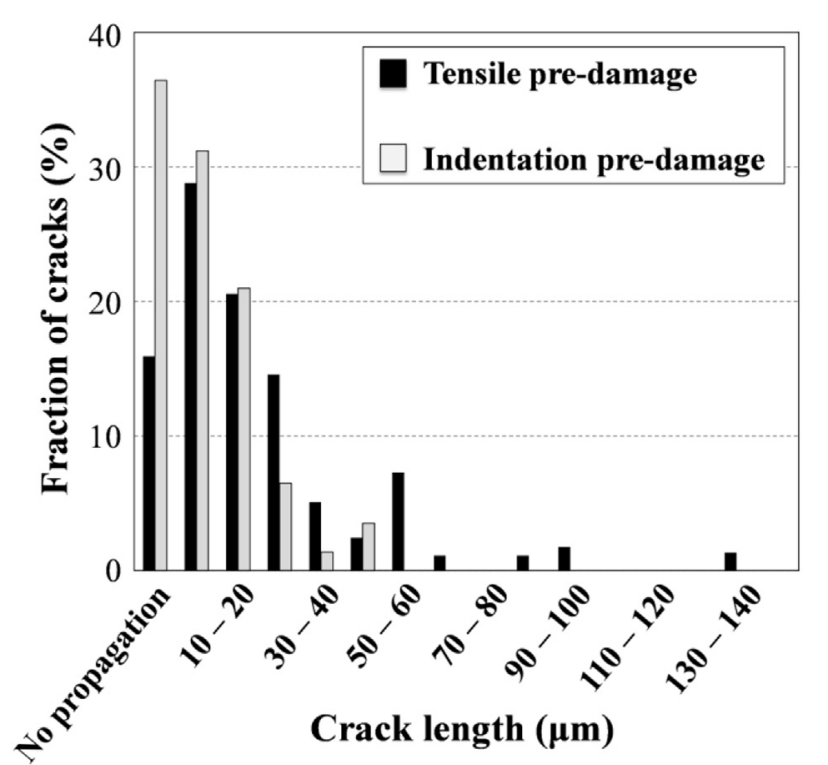

Fig. 5. Distribution of the crack length propagating from pre-cracked NMIs after 10,000 cycles at room temperature for the two ways to introduce pre-damage. The tensile pre-damage, i.e. an overloading prior to fatigue testing, favors short crack propagation from non-metallic inclusions.

forty cracked NMIs were compared in order to statistically evaluate morphological contributions of cracked NMIs in the volume (depth of the NMIs and occurrence of sub-surface NMIs) on the ease of short crack propagation (Fig. 10). Surface and sub-surface clusters of NMIs were evaluated on both surface and cross-section views, depicted as blue-solid-triangle and red-cross markers, respectively. Again, clusters of NMIs favor crack propagation with the surrounding metallic grains, regardless of whether they were surface or sub-surface dominant. While no correlations were found from solely surface observations (Fig. $10 \mathrm{a}$ and $\mathrm{c}$ : $\mathrm{R}^{2}=0.12$ and 0.15 for tensile and micro-indentation pre-damage method using linear regression, respectively), volume analyses better highlighted the straightforward dependency of the crack length within the metallic matrix with the depth on the cross-sectional surface area of the pre-cracked NMIs (Fig. 10b and d). Despite a rather good correlation between the extent of the crack within the metallic matrix and the depth $\left(R^{2}=0.62\right.$ and 0.64$)$ or the cross-section surface area $\left(R^{2}=0.32\right.$ and 0.23$)$ of the pre-cracked NMIs, both of these criteria omit the combination of aspect ratio, size and orientation of cracks, that has a valuable influence on the stress concentration at the crack tip in linear elastic fracture mechanics. Indeed, pre-cracked NMIs having the following morphological parameters did not propagate for those fatigue conditions, regardless the size of the NMI:

Non - propagating criterion $\rightarrow 2 c / a>3.07$

With $2 c$, the crack length within the initiating NMI measured at the surface, and $c$, the depth of the initiating NMI on the FIB cross sections. Therefore, stress intensity factors for isolated pre-cracked NMIs at the surface of the crack were calculated considering precracked NMIs as semi-elliptical surface cracks in a finite-thickness plate [28]. The crack length within the metallic matrix was plotted in Fig. 11 as a function of the stress intensity factor $K$ (Mode I) for an applied uniform stress $\sigma$ far from the NMI (see e.g. eq. (2)). 

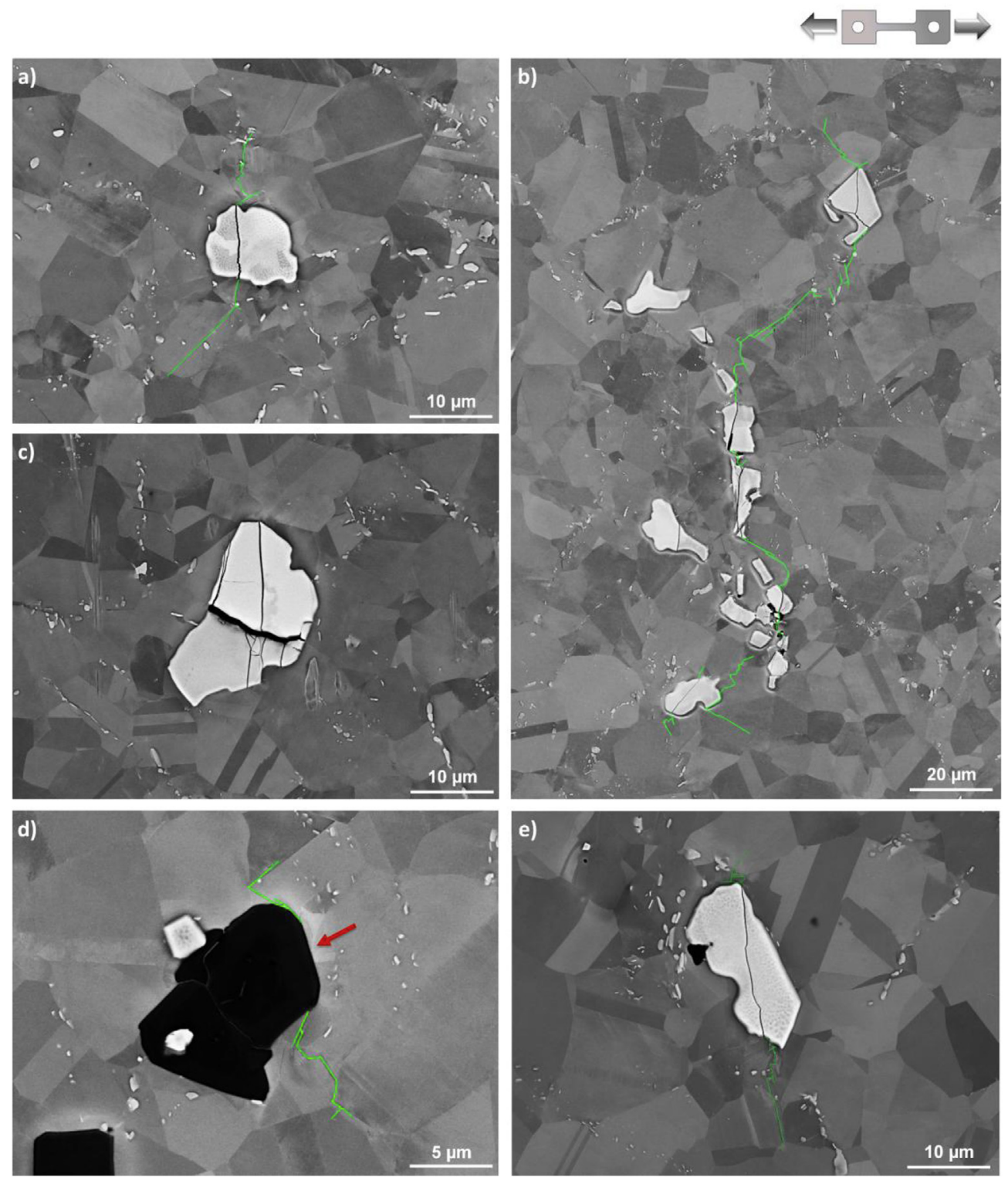

Fig. 6. Typical crack path configurations after 10,000 cycles at room temperature from pre-cracked NMIs via interrupted tensile tests and micro-indentation under uniaxial loading: a) Relatively small carbide propagating, b) Cluster of carbides leading to very long cracks and crack merging, c) Coarse carbide not propagating, d) Non-cracked nitride leading to crack propagation due to NMIs/matrix debonding (the red arrow locates the TiN/matrix debonding), e) Cracked carbonitride due to the applied tensile stress in the elastic domain $(800 \mathrm{MPa})$ for the micro-indentation pre-damage introduction leading to crack propagation. The crack path propagating from the NMIs is highlighted with a green line for reading convenience. (For interpretation of the references to color in this figure legend, the reader is referred to the Web version of this article)

$K=\sigma \sqrt{\pi a / Q} F\left(\frac{a}{c}, \frac{a}{t}, \phi\right)$

$Q=1+1.464(a / c)^{1.65}$ for $a / c \leq 1$

$Q=1+1.464(c / a)^{1.65}$ for $a / c \geq 1$

with $a$ the depth of the initiating NMI on the FIB cross section, $c$ the half-crack length within the initiating NMI, $t$ the sample thickness, $Q$ the shape factor for an elliptical crack, $\phi$ the parametric angle of the ellipse and $F$ the stress-intensity boundary-correction factor. The values of the stress-intensity boundary-correction factor were taken from Ref. [28]. The stress-intensity factor approach was shown not to particularly improve the correlation with the crack length, except for the long cracks, or to be as good as the "depth of pre-cracked NMI" approach $\left(R^{2}=0.54\right.$ and 0.52$)$. However, other criteria might play a significant role on the ease of crack propagation due to the remaining huge discrepancy in the results, such as crystallographic configurations favoring or not crack transmission.

\subsubsection{Crystallographic considerations on the crack propagation capability from pre-cracked NMIs}

As shown above, NMIs cracked in a brittle manner along $\{001\}$ or $\{011\}$ crystallographic cleavage planes. Therefore, the effect of the crystallographic orientation of the pre-cracked NMIs on the crack propagation capability was investigated for all the condition variants (Fig. 12a and b). Pre-cracked NMIs capable of propagating cracks are displayed with square solid markers with a color code representative of the crack length (cold colors corresponding to 

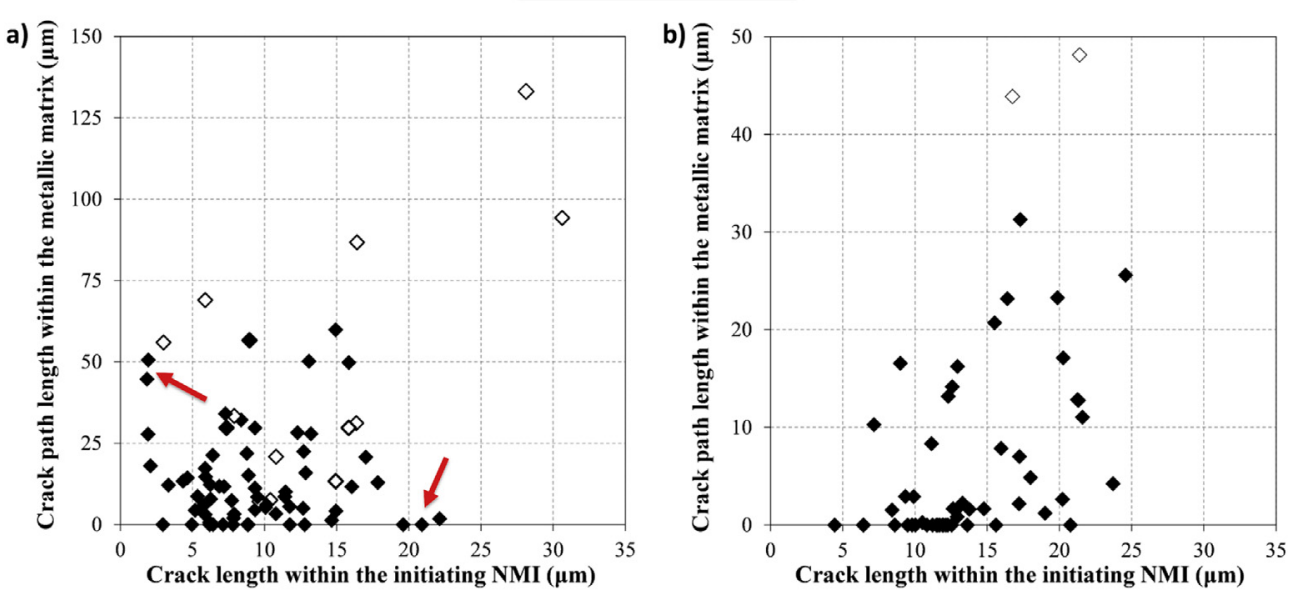

Fig. 7. Morphological investigation of cracks and NMIs from surface observations of the three experimental pancakes after 10,000 cycles for the two pre-damaging conditions: a) pre-damaged by tensile, b) pre-damaged by micro-indentations. Isolated NMIs were differentiated from cluster of NMIs. No significant trends were correlated between the size of the pre-cracked NMIs and the length of the crack propagating within the surrounding metallic matrix, based on surface observations.

short cracks while hot colors corresponding to long cracks) on the standard IPF triangle representation in reference to the loading direction. Non-propagating NMIs are depicted with circular empty markers. Propagating NMIs and non-propagating NMIs were randomly located on the standard triangle, showing no straightforward correlation with the $\{001\}$ and $\{011\}$ orientations. In addition, NMIs were also differentiated in three categories, i.e. carbides, nitrides and carbonitrides, on the standard IPF triangle representation (not shown in Fig. 12a and b for reading convenience). No particular orientation criterion emerges from these analyses per category. Thus, there is no effect of the crystallographic orientation of the NMIs influenced the ease of crack propagation in the surrounding matrix.

Since all the cracks grow in the metallic matrix along $\{111\}$ slip planes, the effect of the crystallographic orientations of the metallic grains in contact with the crack tips within NMIs was also investigated. As for the previous crystallographic investigation, no straightforward correlation was observed between the two latter parameters, as because the crystallographic crack path in the metallic matrix is relatively complex (Figs. 3, 4, Fig. 6). Therefore, mechanisms of crack transmission in the grains in the vicinity of the pre-cracked NMIs were investigated (Fig. 12c and d). Single slip activity (Fig. 13a) and multiple-slip activity (Fig. 13b) in the grain in contact with the pre-cracked NMIs was observed during LCF testing at room temperature. However, no significant differences were found in the crack growth rate as a function of the number of active slip systems. Clusters of NMIs do not necessarily favors two-slip activities crack growth, as illustrated as example in Figs. 3 and 4. Debonding at the NMI/metallic matrix interfaces was also identified as a crack transition mechanism (Fig. 13d). Some NMIs did not propagate (Fig. 13c). Gray-level contrast with bowtie shape was noticed in the metallic grain adjacent to the crack tip (NMIs), representative of local crystal misorientation (white arrows in Fig. 13c).

Crack transmission from both sides of the pre-cracked NMIs was documented for all the cracks investigated in the present study (Fig. 14). The three experimental pancakes were found to similarly behave in terms of occurrence of crack transmission mechanisms. However, some differences were found between the two predamage modes. As mentioned previously, the tensile pre-damage condition favored crack propagation from NMIs, leading to a lower fraction of "non-propagating NMIs" compared to the microindentation pre-damage condition, and inversely to higher fractions of the three other mechanisms to transmit damage: (i) NMI/ metallic matrix debonding, (ii) propagation - single, and (iii) propagation - multiple. In addition, those three latter conditions were shown to be equally distributed for the tensile pre-damage condition, with a slightly higher fraction for the crack mechanism involving a single slip activity in the adjacent grain. For the microindentation pre-damage condition, the NMI/metallic matrix debonding mechanism was found to be statistically less represented than the two other propagating mechanisms. No correlation was also found between the mechanism of crack transmission and the overall length of the crack.

To understand non-propagation from pre-cracked NMI, it was previously demonstrated that $3 \mathrm{D}$ information of the NMI morphology is needed, especially its extent into the sub-surface. Therefore, the three different mechanisms for crack propagation were investigated in terms of crystallographic configurations between the NMI (crack or interface) and the $\{111\}$ active slip planes in the adjacent grain.

For the NMI/metallic interface debonding condition, two different crystallographic conditions were found depending on whether the NMI was a nitride (Fig. 15) or a carbide (Fig. 16). The $\mathrm{NMI} /$ metallic grain interface correspond to NMI crystallographic planes, i.e. $\{001\}$ planes and $\{111\}$ planes for the nitrides (Fig. 15a and b) and carbides (Fig. 16a and b), respectively. It is worth reminding that the [001] is the orientation with the highest stiffness for NMIs, making $\{001\}_{\mathrm{NMI}} /\{\mathrm{hkl}\}_{\text {metallic grain interface a }}$ particular location of stress concentration. It was found that a low misorientation of the $\{111\}$ active slip plane of the adjacent metallic grain is required to initiate debonding for both nitrides and carbides. The active slip plane in the adjacent metallic grain does not necessarily need to be the highest Schmid factor of the grain according to the loading direction, and could be as low as 0.243 , due to the local stress concentrations that arise due to the presence of the hard, angular particles. However, the $\{111\}$ active slip plane parallel with the interface at the surface should not necessarily be parallel to the NMI/metallic grain interface in the volume. This active slip plane has to be transgranular within the metallic grain 

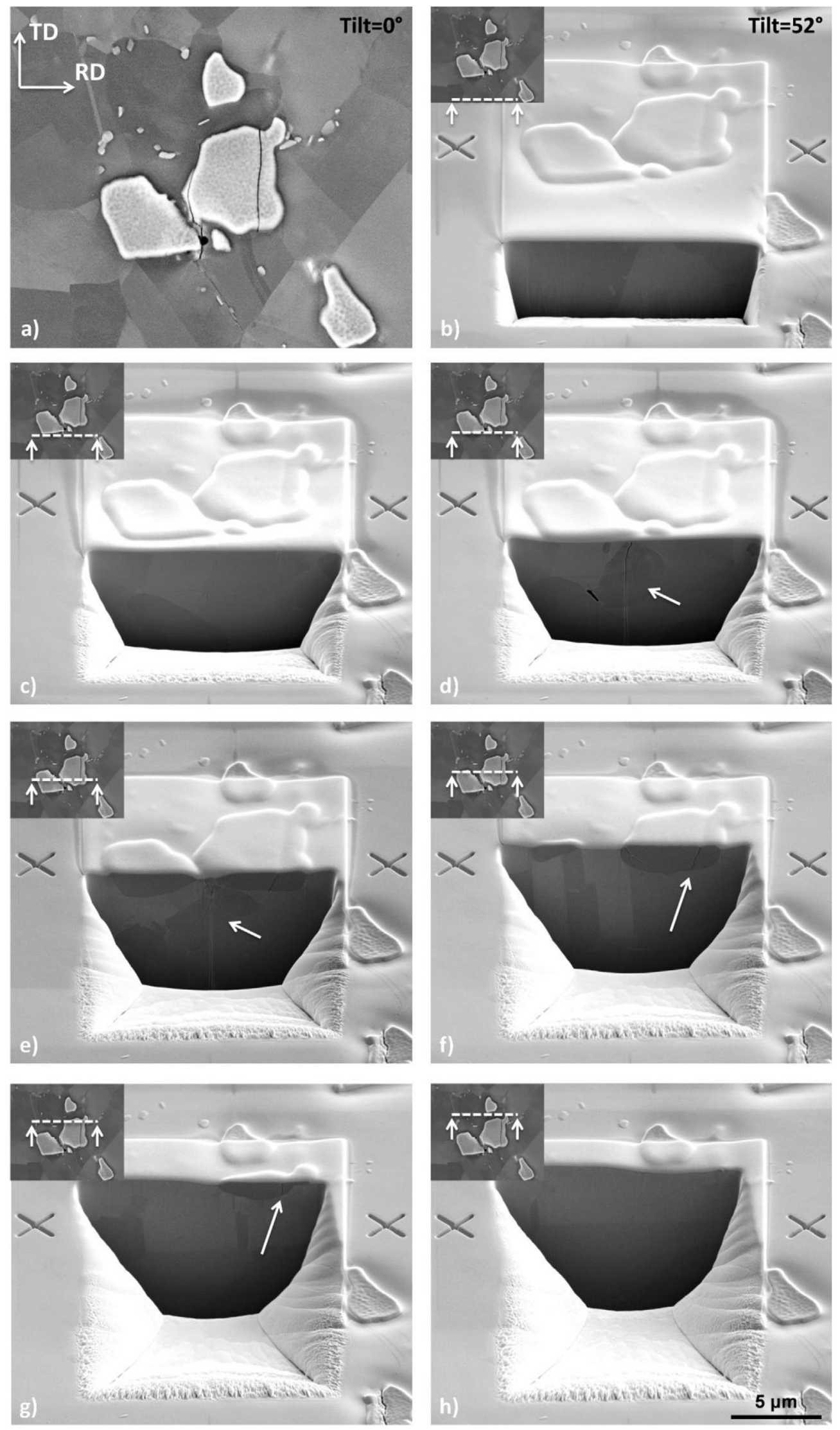

Fig. 8. Serial FIB cross-sections of a cracked carbide. a) Top view of the area of interest before FIB investigation (loading direction along the RD direction). a-h) Serial cross FIB sections at different locations. The Top left corner incrustation illustrates the location of the cross section according to the top view observation. White arrows in d) and e) evidence the presence of a cracked sub-surface carbide. White arrows in $\mathrm{f}$ ) and $\mathrm{g}$ ) highlight the change in cleavage plane within the inclusion. 


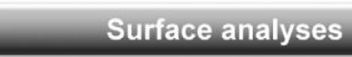

a)
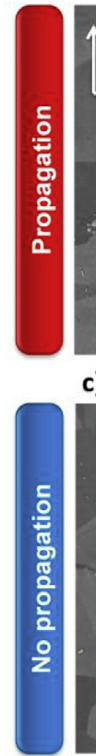

c)

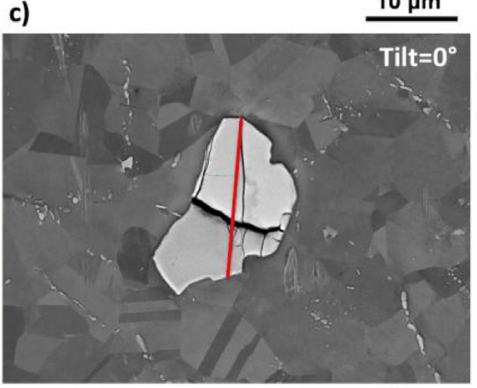

$10 \mu \mathrm{m}$

rack path length within the metallic

Crack length within the initiating NM

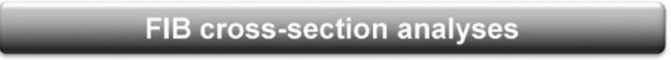

b)

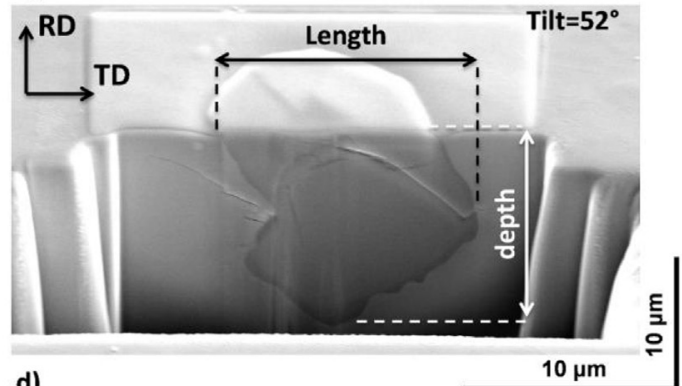

d)

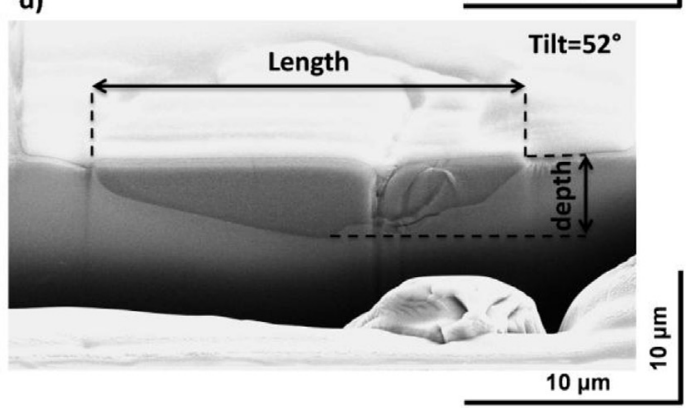

Fig. 9. Surface and cross-section observations of: a and b) a small at the surface but deep carbide leading to crack propagation, c and d) a non-propagating coarse at the surface but shallow carbide.

adjacent to the NMI, with a wide range of misorientation angles possible in the volume (Fig. 15d and Fig. 16d).

For the propagation conditions with one or at least two slip planes, the activated slip planes generally correspond to planes with relatively high Schmid factor according to the loading direction, but not necessarily the highest Schmid factor of the grain. For propagation conditions involving one slip plane, the active plane generally corresponds to the $\{111\}$ plane having the highest Schmid factor and with a value as high as 0.4, as depicted in Fig. 17a. In rare cases, non-maximal and relatively low Schmid factor planes $\left(\mu_{\mathrm{ac}}\right.$ tive $=0.15 \neq \mu_{\max }$ ) lead to crack transmission. However, the origin of such an unexpected crack transmission was not found at this point. For propagation conditions involving at least two slip planes, the active planes generally have surface trace planes highly misoriented and comparable Schmid factors, as shown in Fig. 17b.

\subsubsection{Evolution of pre-cracked NMIs in the volume after the tensile-} pre-damage condition

Surface and sub-surface observations of the pre-cracked NMIs for tensile pre-damage conditions clearly demonstrated the detrimental contribution of surface and sub-surface clustered NMIs on the crack propagation capability (Figs. 9 and 10). This is particularly true when cracks run between the individual NMIs in the cluster, making them an effectively much larger inclusion. Therefore, serial polishing was performed, followed by SEM observations in order to statistically document the fraction of pre-cracked NMIs at different depth locations in the volume of the tensile specimen, from the surface down to $210 \mu \mathrm{m}$ in the volume (Fig. 18). At least two hundred NMIs were randomly observed at each depth location, and the nature of the NMIs was also taken into account for this analysis. It is worth noting that pre-cracked NMIs means cleaved NMIs, the NMI/ metallic grain debonding condition being impossible to capture even at high magnification. It was shown that around 38\% of the NMIs were cracked at the surface, with a slightly higher fraction for the carbonitrides. This fraction of pre-cracked NMIs slightly increased in the volume at a depth of $10 \mu \mathrm{m}$ and then decreased up to a stabilized fraction at $50 \mu \mathrm{m}$ for the nitrides and $90 \mu \mathrm{m}$ for the carbides and carbonitrides. While the fractions of cracked NMIs were mostly equivalent at the surface regardless the nature of the NMIs, the stabilized fraction of cracked nitrides is lower (5\%) than the one of the carbides and carbonitrides cracked in the volume (16-18\%). It is worth mentioning that NMIs debonding could not be documented with this observation technique.

\section{Discussion}

Understanding the first steps of crack propagation from nonmetallic inclusions (NMIs) is essential in order to document the variability in fatigue life experienced by the direct aged version of the Inconel 718 (Ref. [6]). In this study, a particular attention was paid to crystallographic and three-dimensional morphologies of the NMIs and the surrounding grains to correlate to crack growth capability from cracked NMIs. Three experimental pancakes were forged in order to produce microstructures leading to variability in LCF lifespan, i.e. low $\delta$-phase content $\left(f_{\delta \text {-phase }}<3.2 \%\right)$ and grain size microstructure finer than $15 \mu \mathrm{m}$ (Ref. [6]). These experimental wrought pancakes, previously studied in the very high cycle fatigue (VHCF) regime/very low macroscopic elastic deformation region (ref. [7]), were tested in the present study at room temperature in the low cycle fatigue regime. In order to avoid the incubation time associated with crack initiation within NMIs, two methods for precracking NMIs were investigated. As for VHCF testing, pre-straining in the early plastic domain, i.e. "overloading", prior to fatigue testing favored crack propagation due to longer cracks in general, 

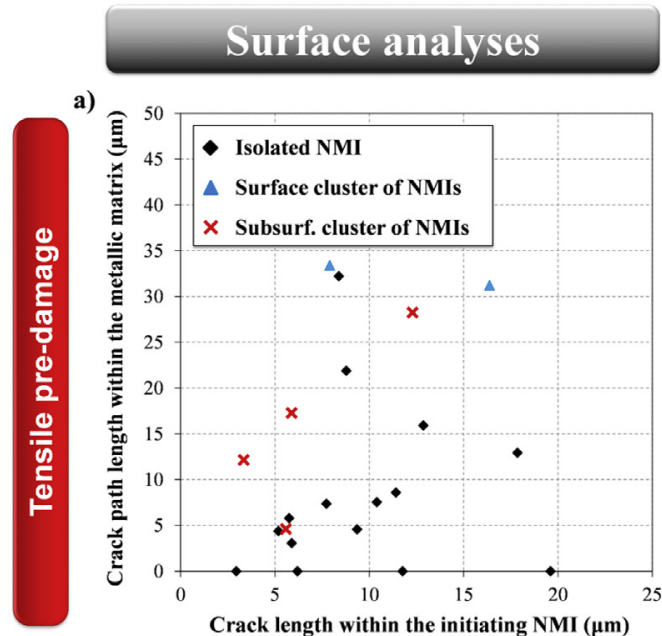

a)
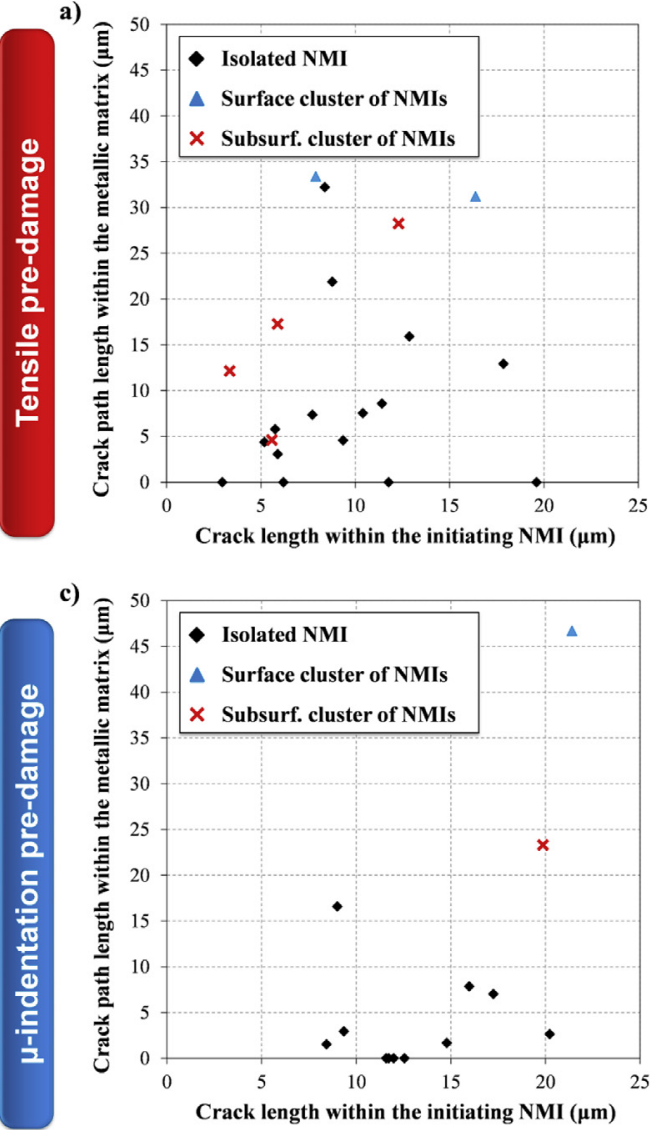

FIB cross-section analyses

b)

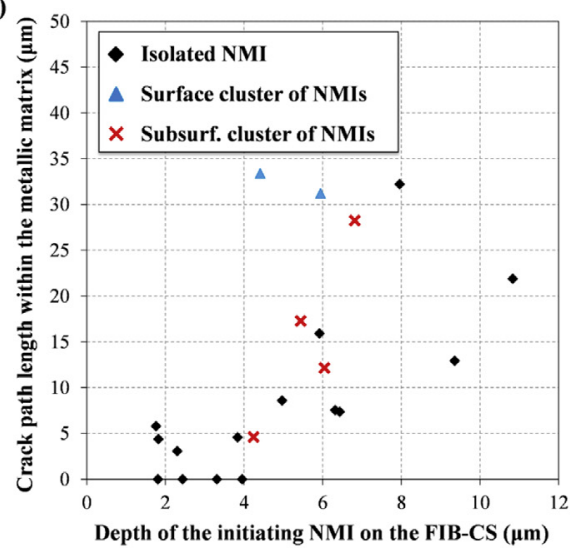

d)

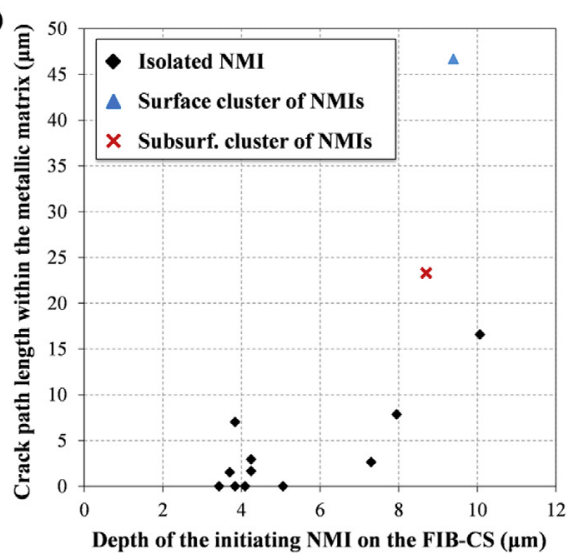

Fig. 10. Morphological influence of cracked NMIs from a, c) surface and b, d) FIB-cross section observations on the crack length after 10,000 cycles of the PAN-1\&2 microstructure pre-damaged by a, b) tensile and c, d) micro-indentation. Clustering effect and the depth of pre-cracked NMIs were found to have a major contribution in the ease of short crack propagation.

but also promote interfacial debonding of the NMIs (Fig. 14). NMIs predominantly failed in a brittle manner along $\{001\}$ and $\{011\}$ cleavage planes (Fig. 1), regardless of the pre-damage method. Furthermore, some NMIs naturally cracked beyond stresses of $800 \mathrm{MPa}$, i.e. $63 \%$ of the maximal cyclic stress. The cracking history of NMIs as a function of the cyclic stress likely has a significant influence on subsequent crack growth, as reported in Refs. [6,7]. The earlier the NMIs crack in the cyclic life, the sooner strain localization within slip bands would develop in the vicinity of the crack tip, leading to an opening of the crack within the NMI. The intense local plasticity in the metallic matrix at the opened crack tip might favor crack transmission via the activated slip systems since irreversible deformation was already present due to the predamage procedures.

Despite crystallographic failure within NMIs, no correlation was found between the orientation of the pre-cracked NMI and the propagating crack length in the neighboring grains (Fig. 12a). NMIs were as large, and in some cases even larger, than the surrounding grains. Since the elastic and plastic anisotropy for nickel-based superalloys and the difference in elastic and plastic behaviors between NMIs and the metallic grains is important, the heterogeneous strain/stress field at the grain scale might participate to the complex and unpredictable failure of NMIs involving several cleavage planes (Fig. 1). Therefore, a cracked NMI may or may not propagate into the surrounding grains, independent of its crystallographic orientation due to neighborhood effects (Fig. 12a).

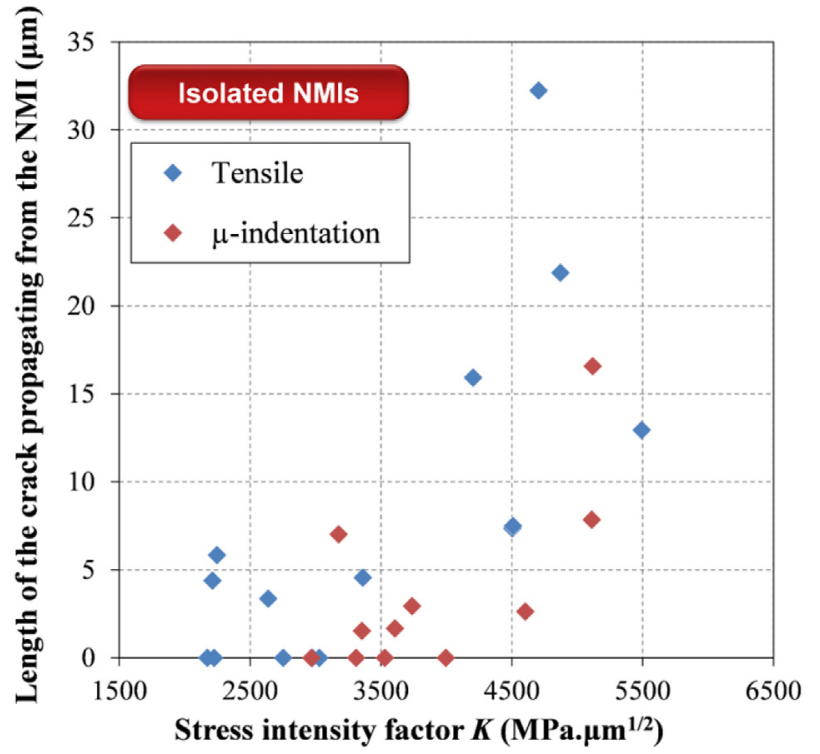

Fig. 11. Crack path length as a function of the stress intensity factor after 10,000 cycles of the PAN-1\&2 microstructure for the two ways to pre-damage NMIs $\left(\sigma_{\max }=1375 \mathrm{MPa}\right)$. Comparative effects of the stress intensity factor and the depth of the pre-cracked NMIs were found to predict the ease of crack propagation. Secondary effects, such as crystallographic effects, are expected to account for the variability in the results. 

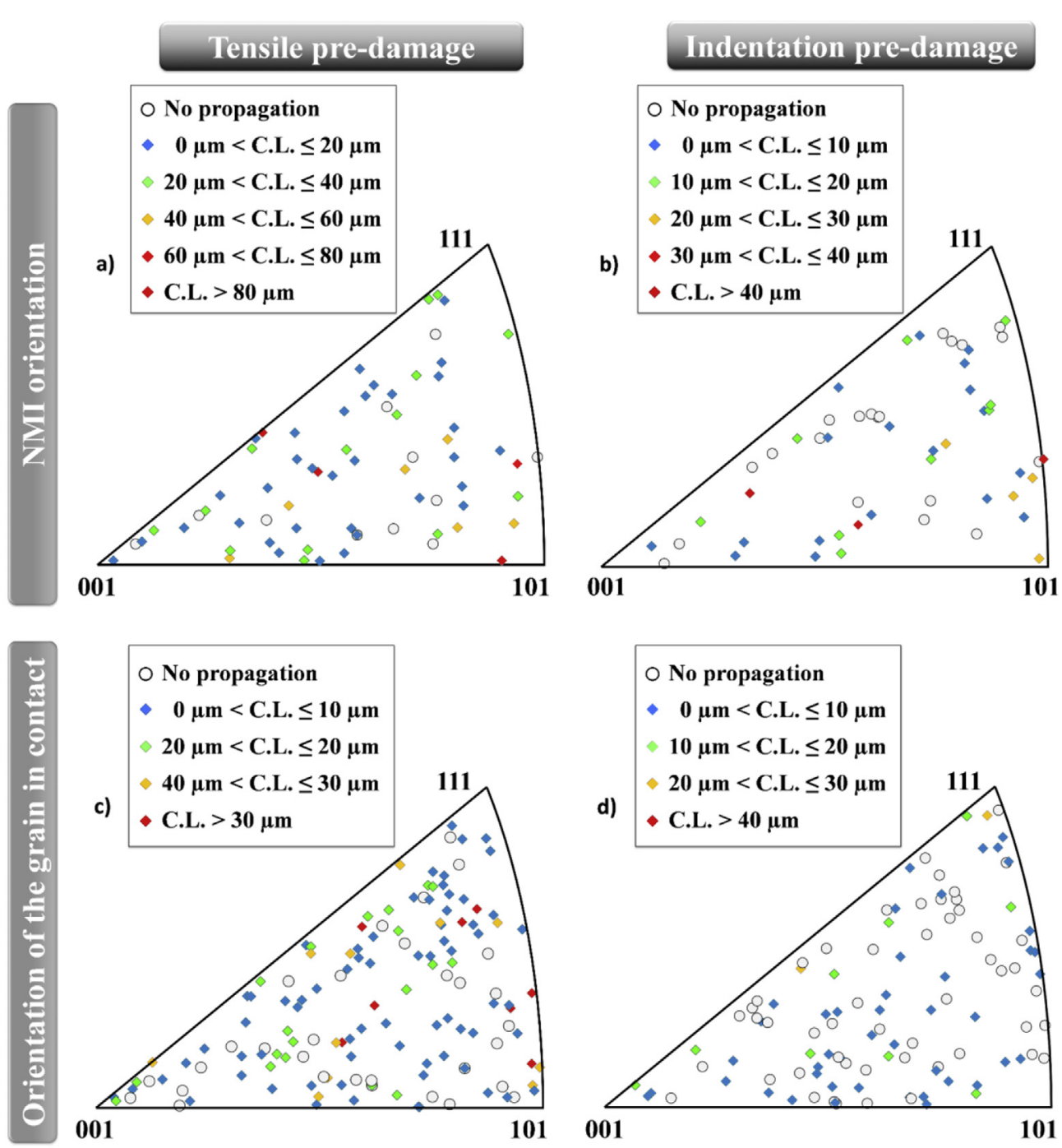

Fig. 12. Correlation between the crystallographic orientation of a, b) the cracked NMIs or c, d) the grain in contact and the crack length (C.L.) for the three experimental pancakes after 10,000 cycles for the two pre-damaging conditions. No correlation was found between neither the initial orientation of the NMI or the orientation of the grain in contact and the crack length despite NMIs cleavage according to $\{001\}$ and $\{011\}$ crystallographic planes.

Furthermore, the crystallographic orientation of the grains adjacent to the cracked NMIs did not have a straightforward relationship to the ease of crack propagation from the NMI into the surrounding metallic grains (Fig. 12b). Indeed, for the testing conditions investigated, four different mechanisms of crack transmission were found, (i) no propagation, (ii) NMI/adjacent metallic grain interfacial debonding and, transgranular propagation within the adjacent grain involving (iii) along one slip plane, and (iv) at least two slip planes. Because of this variability in mechanisms of crack transmission, specific crystallographic and morphological criteria were found necessary to activate one specific mechanism. A detailed discussion on the crystallographic and morphological considerations is presented in the following sections.

Based on the present systematic investigation of crack propagation from non-metallic inclusions (NMIs) in IN718DA and previous studies [6,7,29], detrimental microstructural features were identified and could be taken into account for further design improvement of fine-grain Ni-based IN718DA superalloys (ASTM 9 to 12 , i.e. less than $15 \mu \mathrm{m}$ in grain size). It is worth noting that IN718DA superalloys demonstrate higher fatigue performances than standard IN718, but with a greater fatigue life variability that limits the proper use of this high performance material. Probabilistic approaches are thus useful lifing methodologies to take into account such a variability in the actual design of structural components made of IN718DA. While surface and sub-surface NMIs could not be avoided when manufacturing structural components (NMIs nucleate/grow during melting stages of the ingots), mastering NMIs size, their morphology and distribution within wrought components appear necessary to avoid discrepancy and variability in the fatigue life. Large NMIs (i.e. larger than the coarser metallic grains), regardless of their chemical nature ( $\mathrm{NbC}$, TiN and NbCTiN), are prone to early crack initiation and propagation into the metallic matrix, leading to abnormally short fatigue life $[6,7]$. Therefore, refining grains to gain in fatigue performance requires the concomitant refinement in NMIs. NMIs refinement could be obtained during the ingot remelting, the forging operations but also using addition-elements. In addition, NMIs clustering was also found particularly harmful for crack propagation as long as the original cracked NMI within the cluster is large enough and surrounding NMIS close enough to propagate a crack. Therefore, the conjunction of large NMI plus NMIs clustering is thought to be the worst microstructural configuration leading to abnormally and 

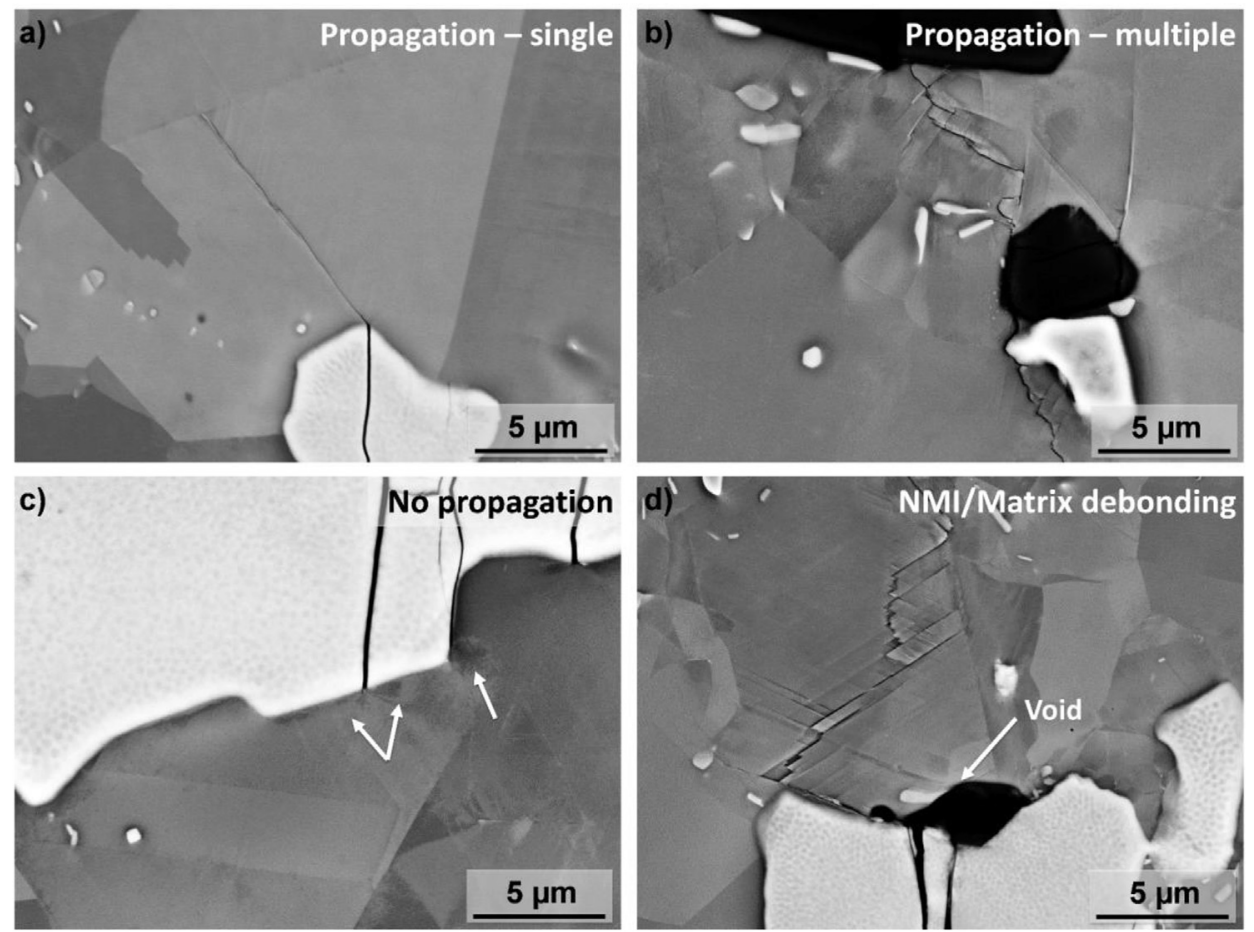

Fig. 13. Different crack transmission modes from pre-cracked NMIs to the surrounding metallic grains. a) Single slip activity in the grain in contact, b) multiple slip activity in the grain in contact, c) No propagation in the grain in contact, d) debonding at NMI/grain interface. A void is also present in the vicinity of the crack.

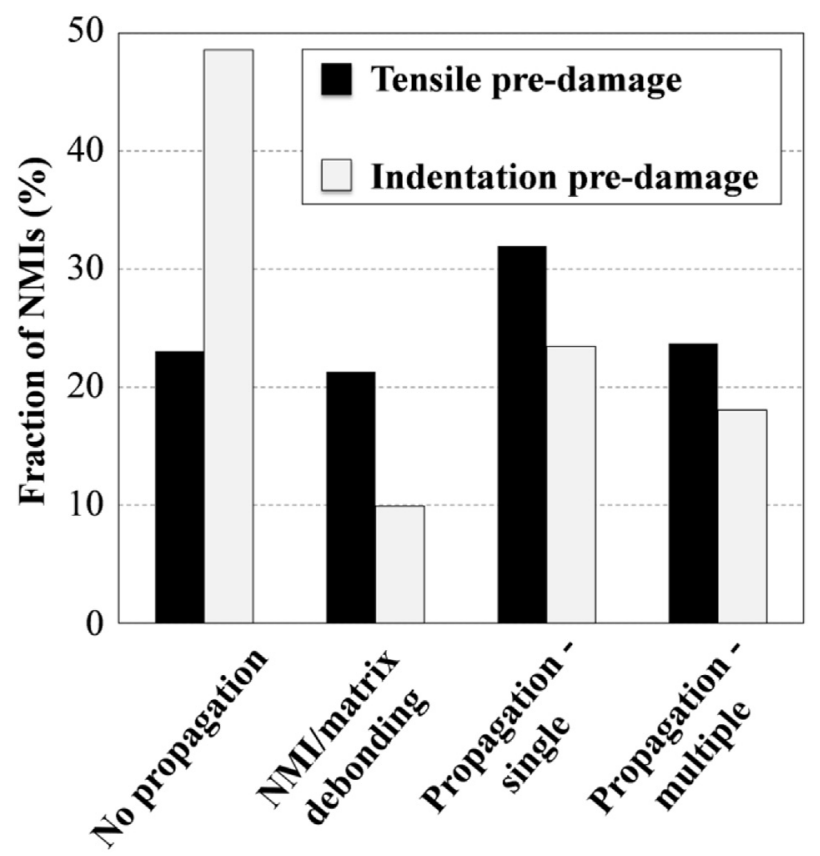

Fig. 14. Illustration of the fraction of pre-cracked NMIs leading to one specific mechanism of crack transmission in the grain in contact of the pre-crack tip, i.e. No propagation, NMI/metallic matrix debonding, propagation with one active slip system, or propagation with at least two active slip systems.

unpredictable short fatigue life. Macrosegregations, at the origin of such NMIs clustering, have to be avoided for the manufacturing of fine-grain $\mathrm{Ni}$-based superalloys and multiple vacuum remelting operations are necessary prior to forge such IN718DA grade.

\subsection{Morphological effects on the crack propagation capability}

The NMIs present in these forged pancakes possessed complex and unpredictable morphologies that required full 3D characterization (Fig. 9). Therefore, sole surface observations of NMIs are not representative for estimating the initial defect size associated with crack propagation. No straightforward correlations were found between the surface dimensions of the NMIs and the crack length propagating from those NMIs (Fig. 7). Indeed, the largest NMIs at the surface result in no propagation, and inversely smaller surface NMIs that extend more deeply into the sub-surface did propagate (Fig. 7a). FIB-cross section analyses were found valuable, giving access to the unpredictable "surface crack length within NMI/NMI depth" ratio (Fig. 9). Cross-section characterizations aimed to improve correlations between the size of the initial crack and the crack length within the surrounding grains (Fig. 11). It was shown that the "no-propagation" condition follow a morphological criterion. Indeed, pre-cracked NMIs large at the surface $(2 c)$ with limited extension into the depth (a) did not propagate when $2 c / a>3.07$, regardless of the size of the NMIs for this specific LCF condition. In addition to this, FIB-cross-section characterization (Figs. 8 and 15) showed that clustering could not be predictable from solely surface observations. NMI clustering, either sub-surface or surface clustering, favored crack propagation, as shown in Fig. 10. Denda et al. reported via fractographic analyses a straightforward correlation between the size of surface NMIs (depth of the NMIs) and the fatigue life at intermediate temperatures when using remelting techniques in order to lower the content and the size of NMIs in vacuum induction melted IN718 alloy [10]. Recent studies also reported that cluster of NMIs in the volume could lead to atypically short fatigue life [6]. NMIs clustering was not a necessary condition to promote abnormally short fatigue life since isolated but deep 


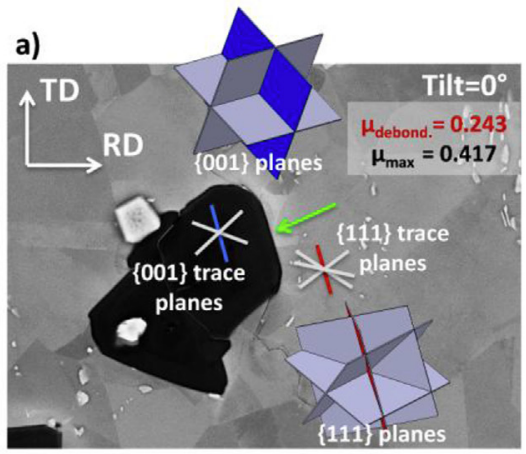

c)
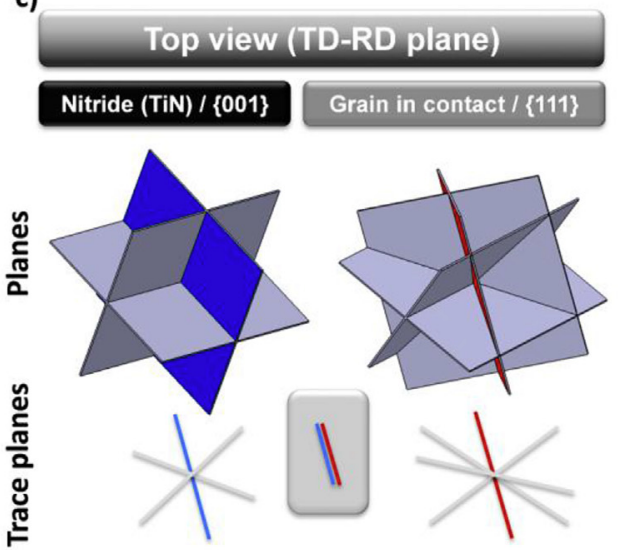

b)

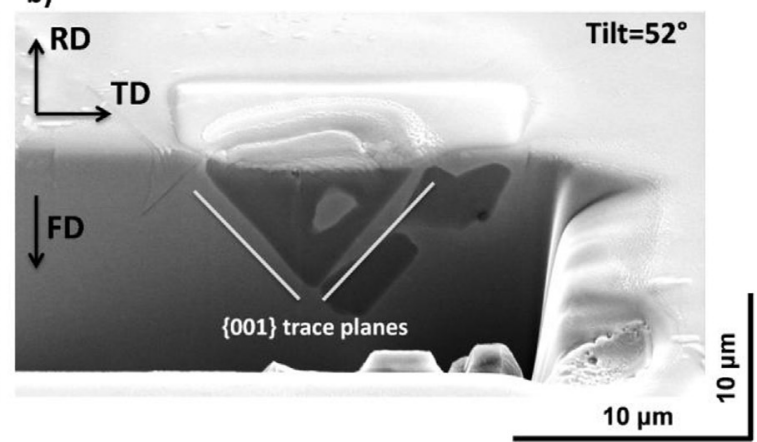

d)

Cross-section view (RD-FD plane)

Nitride (TiN) / \{001\} Grain in contact / \{111\}

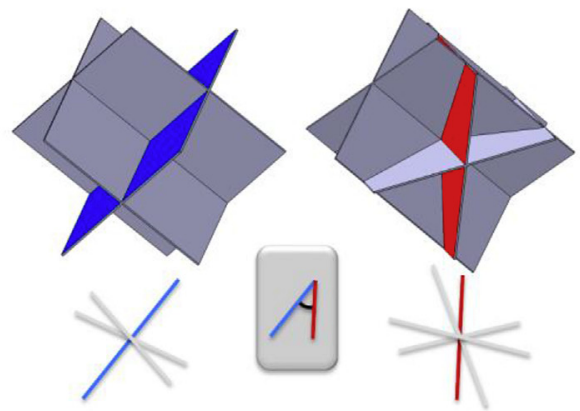

Fig. 15. Crystal configurations enabling nitride/metallic matrix debonding. The debonded interface is depicted with a green arrow. The $\{001\}$ and $\{111\}$ planes and trace planes were illustrated for the nitride and the adjacent metallic grain, respectively. The blue plane and red plane correspond to the plane of the nitride and the metallic grain parallel to the debonded interface, respectively. The Schmid factor of the active $\{111\}$ plane according to the loading direction (horizontal direction) is relatively low. a) Surface observation showing that the debonded nitride/metallic matrix interface correspond to a $\{001\}$ trace plane of the nitride and that the $\{111\}$ trace active slip plane in the adjacent grain is parallel to the interface. b) FIB cross-section observation of the nitride demonstrating that nitride/metallic matrix interfaces also correspond to \{001\} planes in the volume. This figure also depicts a sub-surface cluster of nitrides not visible via surface observations. Crystal configurations demonstrating the c) necessary low misorientation angle between the $\{001\}_{\text {nitride }}$ and the $\{111\}_{\text {metallic grain }}$ at the surface, and d) not necessarily low misorientation angles between the $\{001\}_{\text {nitride }}$ and the $\{111\}_{\text {metallic grain }}$ in the volume for the debonding condition. (For interpretation of the references to color in this figure legend, the reader is referred to the Web version of this article)

NMIs can also be at the origin of premature cracking under various fatigue conditions (Refs. [6,7]). FIB-cross section characterizations of surface secondary cracks aimed to statistically document morphological requirements of cracked NMIs to promote crack propagation in the surrounding grains, as conventionally documented via fractographic observations of numerous fatigued specimens. In contrast to fractographic analyses, the FIB-cross section characterization allowed for identification of nonpropagating configurations, i.e. large cracked NMIs at the surface with limited extension into the depth.

\subsection{Crystallographic effects on the crack propagation capability}

Morphological aspects of pre-cracked NMIs play a critical role in the crack propagation capability under LCF loading conditions (Figs. 9, Figs. 10 to 11). However, discrepancy in the results when solely plotting morphological criteria of the pre-cracked NMIs suggests that neighborhood effects, such as crystallographic configurations, are also considerations to take into account. In the LCF regime for such a multiphase material, both the elastic properties at the grain scale and the strain localization within slip bands in the vicinity of cracked NMIs are relevant parameters for the early stages of crack transmission from NMIs. Different mechanisms of crack transmission from cracked NMIs were found in the present investigation, including $\mathrm{NMI} /$ metallic grain interfacial debonding and transgranular crack propagation, and their origin is discussed in more detail below.

For the B1-cubic and A1-fcc crystallographic structures of the NMIs (carbide, nitride and carbonitride) and the $\gamma$-nickel metallic matrix respectively, Young's moduli along the loading direction range from 124 to $318 \mathrm{GPa}, 417-556 \mathrm{GPa}$ and 416-579 GPa for the metallic matrix Alloy IN718, TiN and NbC, respectively [30-32]. Due to crystallographic structures, $<001>$ and $<111>$ crystallographic directions correspond to the lowest and highest stiffness for the $\gamma$-nickel metallic matrix, respectively. Conversely, <001> and $<111>$ crystallographic directions correspond to the highest and lowest stiffness for NMIs, respectively. The difference in elastic properties between NMIs and the metallic matrix can be as large as $445 \mathrm{GPa}$ at the grain scale, depending on the misorientation between the two materials. This difference in elastic properties between the two phases is two times higher than the one within the metallic matrix $\left(\Delta \mathrm{E}_{\max }(\gamma-\mathrm{Ni}\right.$ phase $\left.)=195 \mathrm{GPa}\right)$. This difference in elastic properties locally leads to stress concentration in the vicinity of these specific configurations, potentially leading to crack initiation/propagation under cyclic loading. As illustrated in Figs. 15 and 16 , blocky nitrides and carbides were demonstrated to have interfaces parallel to specific crystallographic planes, i.e. the $\{001\}$ and $\{111\}$ planes, respectively. This blocky morphology [7,33] is due to diffusion controlled mechanism of NMIs partitioning elements from the surrounding liquid metal during the solidification process 
a)

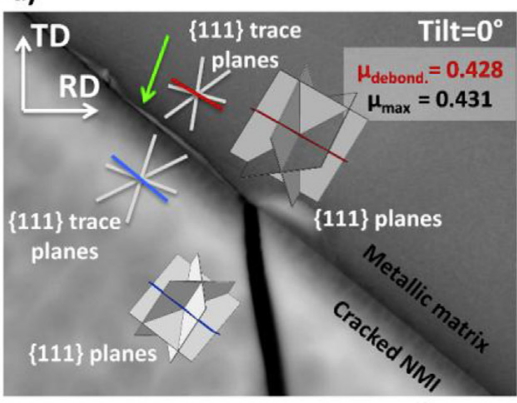

5 нm

c)
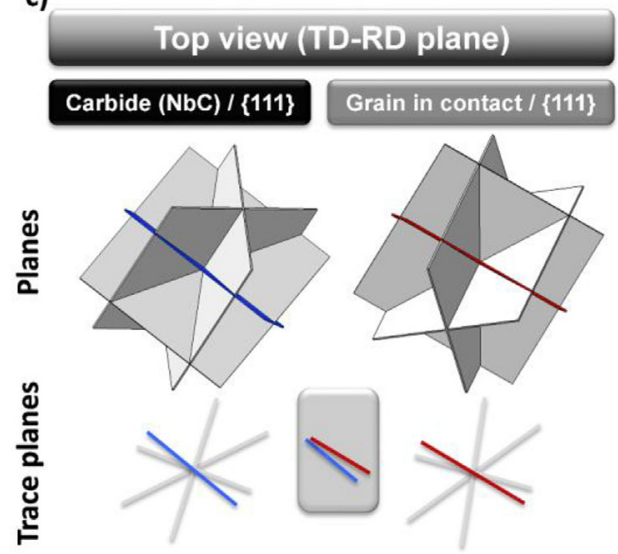

b)

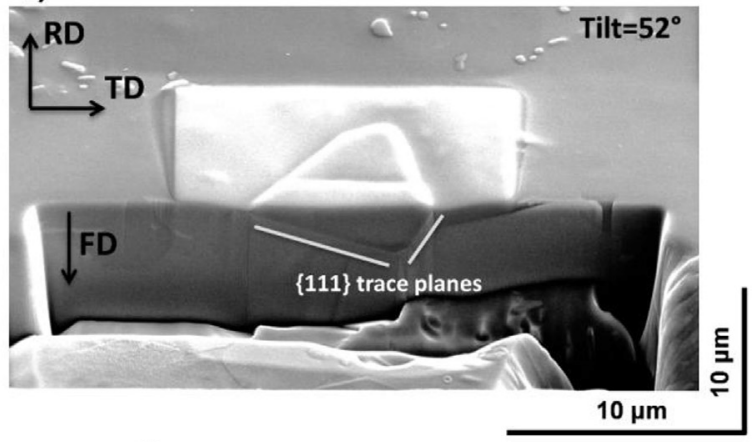

d)

Cross-section view (TD-FD plane)

Carbide (NbC) / $\{111\}$ Grain in contact / \{111\}

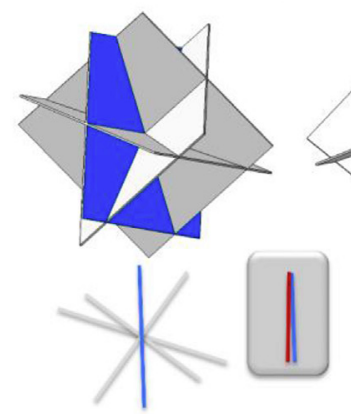

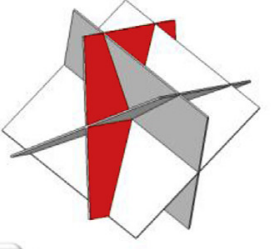

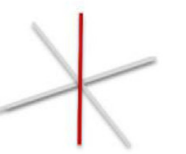

Fig. 16. Crystal configurations enabling carbide/metallic matrix debonding. The debonded interface is depicted with a green arrow. The $\{111\}$ planes and trace planes were illustrated for both the carbide and the adjacent metallic grain. The blue plane and red plane correspond to the plane of the carbide and the metallic grain parallel to the debonded interface, respectively. The Schmid factor of the active $\{111\}$ plane according to the loading direction (horizontal direction) is relatively high and close to the maximal Schmid factor value. a) Surface observation showing that the debonded carbide/metallic matrix interface correspond to a $\{111\}$ trace plane of the carbide and that the $\{111\}$ trace active slip plane in the adjacent grain is nearly parallel to the interface. b) FIB cross-section observation of the carbide demonstrating that carbide/metallic matrix interfaces also correspond to $\{111\}$ planes in the volume. Crystal configurations demonstrating the c) necessary low misorientation angle between the $\{111\}_{\text {carbide }}$ and the $\{111\}_{\text {metallic grain }}$ at the surface, and d) low misorientation angle between the $\{111\}_{\text {carbide }}$ and the $\{111\}_{\text {metallic grain }}$ in the volume for the debonding condition. (For interpretation of the references to color in this figure legend, the reader is referred to the Web version of this article)

a)

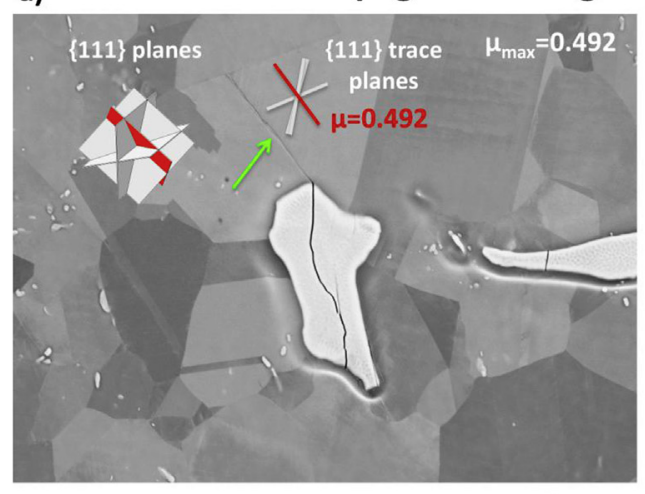

$5 \mu \mathrm{m}$ b)

\section{Propagation - multiple}

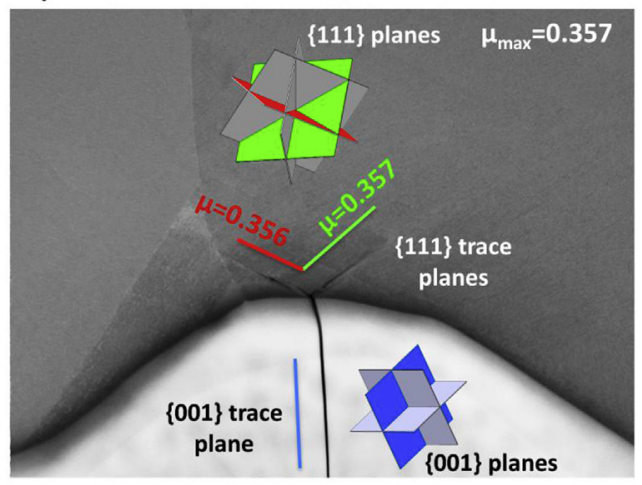

$1 \mu \mathrm{m}$

Fig. 17. Propagation condition from a cracked NMI involving a) one active slip plane with a relatively high Schmid factor $\left(\mu_{\text {active }}=\mu_{\max }=0.492\right)$, b) at least two slip planes with a comparable Schmid factors and close or equal to the maximal Schmid factor value ( $\mu_{\text {active } 1} \approx \mu_{\text {active } 2}=\mu_{\max }=0.357$ ).

[33-35]. It was demonstrated in the present study that when there is alignment of the $\{001\}_{\mathrm{TiN}}$ or $\{111\}_{\mathrm{NbC}}$ plane and a $\{111\}_{\gamma \text {-matrix }}$ metallic grain, interfacial debonding was a possible crack initiation mechanism leading to crack propagation in the surrounding metallic grains (Figs. 13, 15 and 16). Both the deformation incompatibility at this interface and the potential plastic activity parallel to this interface favor the occurrence of this debonding crack transmission mechanism. Interestingly, overload prior to LCF testing was reported to weaken such interface and promote this cracking mechanism from pre-cracked NMs pre-strained in the early plastic regime (Fig. 14). Accumulation of plastic deformation at the NMIs/metallic grain interface under cyclic loading was reported in the literature via finite element calculations [36,37]. In addition, thermal strains in the metallic matrix surrounding 


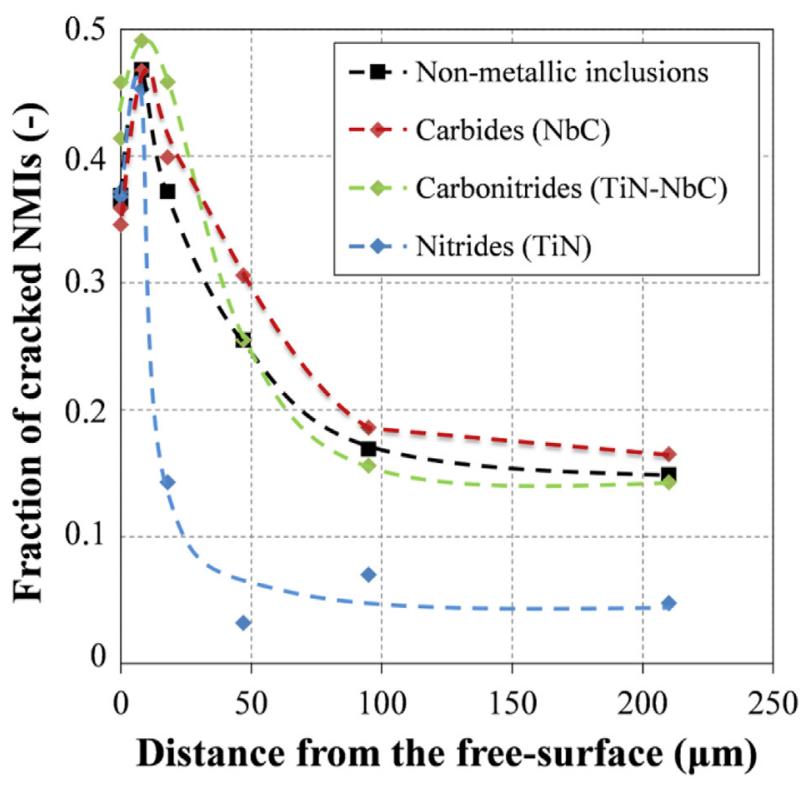

Fig. 18. Evolution of the fraction of cracked NMIs as a function of the depth for a prestrained specimen corresponding to the tensile pre-damage condition.

carbides following standard heat treatments were reported in the literature using high resolution EBSD techniques [16,38]. Such thermal strains result from the difference in thermal expansion properties between NMIs and the metallic matrix, NbC experiencing higher difference in coefficient of thermal expansion $\left(\alpha_{\mathrm{NbC}}=6.6 \times 10^{-6 \circ} \mathrm{C}^{-1}[39]\right)$ with IN718 $\left(\alpha_{\mathrm{IN718}}=13 \times 10^{-6 \circ} \mathrm{C}^{-1}\right.$ [40]), compared to TiN $\left(\alpha_{\mathrm{TiN}}=9.3 \times 10^{-6{ }^{\circ}} \mathrm{C}^{-1}\right.$ [39]). After cycling loading, high geometrically-necessary dislocation (GND) density and deformations were found in the vicinity of carbides, resulting in carbides/metallic matrix debonding in some cases [16]. Beyond this strain localization phenomenon at the interface due to high difference in elastic-plastic behavior between the two media, partially debonded non-metallic inclusions embedded in a metallic matrix subjected to cyclic loadings were shown more damaging than a pre-cracked NMIs $[36,37,41,42]$. In the present study, the interfacial debonding mechanism did not necessarily promote longer cracks since the slip transfer from metallic grain to metallic grain is also an important parameter to take into account for short crack propagation [43].

For transgranular crack propagation (single and multiple), insitu tensile and fatigue testing demonstrated that NMIs easily crack under uniaxial loading in the early plastic regime at room and intermediate temperatures, but plasticity transmission or crack growth does not easily result from pre-cracked NMIs to the surrounding metallic grains under monotonic or cyclic loading $[6,7,44]$. However, strain localization in the vicinity of NMIs in nickel-based superalloys was also evidenced via high resolutiondigital correlation (HR-DIC) techniques, showing intense slip activities in regions subjected to strain concentration due to morphological consideration of biphasic materials, i.e. convex angular regions [29,45-47]. Intense deformation localized within slip bands in these regions also highlights the potential occurrence of transgranular cracking in the grain adjacent to the NMIs, especially when NMIs are pre-cracked.

\section{Conclusion}

The short crack propagation behavior of the IN718DA alloy from non-metallic inclusions (NMIs) was investigated under low cycle fatigue conditions at room temperature. Both crystallographic and morphological considerations were taken into account in order to document the capability of cracked brittle NMIs to transmit crack in the surrounding metallic matrix. Some conclusions from the present work are detailed below:

- Two methods for pre-cracking NMIs, pre-straining in uniaxial tension and micro-indentation, were investigated to avoid the crack initiation incubation time during low cycle fatigue. NMIs cracked in a brittle manner along a combination of $\{001\}$ and/or $\{101\}$ cleavage planes, regardless the pre-damage condition.

- NMIs clustering at the surface or slightly sub-surface in the volume increased the crack propagation capability from precracked NMIs. FIB-cross sections were essential for quantification of clustering.

- Four different crack propagation scenarios for pre-cracked inclusions were observed: (i) no propagation, (ii) NMI/metallic matrix interfacial debonding, transgranular propagation involving (iii) one slip plane, and (iv) at least two slip planes. The tensile pre-damage condition favors crack propagation (lower fraction of the no-propagation condition and longer cracks) and also the interfacial debonding mechanism due to a greater degree of plasticity in the surrounding grains.

- The conditions for "no propagation" were associated with a crack length/crack depth ratio higher than 3 .

- For the debonding condition, differences were found for carbides and nitrides, the interfacial plane being $\{111\}$ and $\{100\}$ for the carbide and the nitride, respectively. The active $\{111\}$ trace slip plane of the adjacent metallic grain have to be parallel (low misorientation required) to the surface trace interfacial plane.

- For transgranular propagation, a high Schmid factor according to the loading direction favors crack propagation involving one active slip plane, while grains having two \{111\} slip systems with comparable Schmid factors favor crack propagation involving at least two active slip planes, i.e. a zigzag crack propagation. High Schmid factors were shown not to be a necessary condition for the capability of the crack to propagate, as long as the three dimension morphological criterion is fulfilled.

\section{Acknowledgement}

The authors are grateful to SAFRAN Aircraft Engines for providing materials and financial support. The authors would like to thank Eric Andrieu from CIRIMAT in France for stimulating discussions on short crack propagation from non-metallic inclusions. The authors are grateful to Stephan Kramers (UCSB) and Florence Hamon (Pprime institute) for help in the FIB characterization and mechanical testing.

\section{Appendix A. Supplementary data}

Supplementary data to this article can be found online at https://doi.org/10.1016/j.actamat.2018.11.051.

\section{References}

[1] T.M. Pollock, S. Tin, Nickel-based superalloys for advanced turbine engines: chemistry, microstructure , and properties, J. Propul. Power 22 (2006) 361-374, https://doi.org/10.2514/1.18239.

[2] C.T. Sims, A history of superalloy metallurgy for superalloy metallurgists, in: Superalloys 1984, Champion (USA), 1984, pp. 399-419, https://doi.org/ 10.7449/1984/Superalloys_1984_399_419.

[3] A. Pineau, S.D. Antolovich, High temperature fatigue of nickel-base superalloys - a review with special emphasis on deformation modes and oxidation, Eng. Fail. Anal. 16 (2009) 2668-2697, https://doi.org/10.1016/ j.engfailanal.2009.01.010. 
[4] D.D. Krueger, The development of direct age 718 for gas turbine engine disk applications, in: Superalloys 718 Metall. Appl., Pittsburgh (USA), 1989, pp. 279-296, https://doi.org/10.7449/1989/Superalloys_1989_279_296.

[5] Y.C. Fayman, Microstructural characterization and elemental partitioning in a direct-aged superalloy (DA 718), Mater. Sci. Eng. 92 (1987) 159-171, https:// doi.org/10.1016/0025-5416(87)90166-2.

[6] D. Texier, A Casanova Gomez, S, Pierret, J-M. Franchet, T.M. Pollock P. Villechaise, J. Cormier, Microstructural features controlling the variability in low cycle fatigue properties of alloy Inconel 718DA at intermediate temperature, Metall. Mater. Trans. A. 47 (2016) 1096-1109, https://doi.org/10.1007 s11661-015-3291-8.

[7] D. Texier, J. Cormier, P. Villechaise, J.C Stinville, CJ. Torbet, S. Pierret, T.M. Pollock, Crack initiation sensitivity of wrought direct aged alloy 718 in the very high cycle fatigue regime: the role of non-metallic inclusions, Mater. Sci. Eng. A. 678 (2016) 122-136, https://doi.org/10.1016/j.msea.2016.09.098.

[8] P.R. Bhowal, A.M. Wusatowska-sarnek, Carbides and their influence on notched low cycle fatigue behavior of fine-grained IN718 gas turbine disk material, in: Superalloys 718, 625, 706 and Various Derivatives, 2005, pp. 341-349, https://doi.org/10.7449/2005/Superalloys_2005_341_349. Pittsburgh (USA)

[9] B. Pieraggi, J.F. Uginet, Fatigue and creep properties in relation with alloy 718 microstructure, in: Superalloys 718, 625, 706 and Various Derivatives, 1994 pp. 535-544, https://doi.org/10.7449/1994/Superalloys_1994_535_544. Pittsburgh (USA).

[10] T. Denda, P.L. Bretz, J.K. Tien, Inclusion size effect on the fatigue crack propagation mechanism and fracture mechanics of a superalloy, Metall. Trans. A 23 (1992) 519-526, https://doi.org/10.1007/BF02801169.

[11] L.A. James, W.J. Mills, Effect of heat-treatment and heat-to-heat variations in the fatigue-crack growth response of alloy 718, Eng. Fract. Mech. 22 (1985) 797-817, https://doi.org/10.1016/0013-7944(85)90109-2.

[12] N. Späth, V. Zerrouki, P. Poubanne, J.Y. Guedou, 718 superalloy forging simulation: a way to improve process and material, in: Superalloys 718, 625 706 and Various Derivatives, 2001, pp. 173-183, https://doi.org/10.7449/ 2001/Superalloys_2001_173_183. Pittsburgh (USA).

[13] F. Alexandre, S. Deyber, a. Pineau, Modelling the optimum grain size on the low cycle fatigue life of a Ni based superalloy in the presence of two possible crack initiation sites, Scripta Mater. 50 (2004) 25-30, https://doi.org/10.1016/ j.scriptamat.2003.09.043.

[14] F. Alexandre, R. Piques, S. Deyber, A. Pineau, High temperature creep-fatigue crack initiation in 718-DA Ni based superalloy, in: Fract. Mech. Beyond 2000 ECF14, Cracow (Poland), 2002.

[15] F. Alexandre, Aspects probabilistes et microstructuraux de l'amorçage des fissures de fatigue dans l'alliage INCO 718, PhD Dissertation, Ecole des Mines de Paris, 2004

[16] P. Kontis, D.M. Collins, S. Johansson, AJ. Wilkinson, JJ. Moverare, R.C. Reed, Crack initiation and propagation during thermal-mechanical fatigue of In792: effects of dwell time, in: Superalloys 2016, Champion (USA), 2016, pp. 763-772, https://doi.org/10.1002/9781119075646.ch82.

[17] T. Connolley, M.J. Starink, P.A.S. Reed, Effect of oxidation on high temperature fatigue crack initiation and short crack growth in Inconel 718, in: Superalloys 2000, Champion (USA), 2000, pp. 435-444, https://doi.org/10.7449/2000/ Superalloys_2000_435_444.

[18] T. Connolley, P.A.S. Reed, M.J. Starink, Short crack initiation and growth at $600^{\circ} \mathrm{C}$ in notched specimens of Inconel718, Mater. Sci. Eng. 340 (2003) 139-154, https://doi.org/10.1016/S0921-5093(02)00169-7.

[19] J.K. Hong, N.K. Park, S.J. Kim, C.Y. Kang, Microstructures of oxidized primary carbides on superalloy Inconel 718, Mater. Sci. Forum 502 (2005) 249-256, https://doi.org/10.4028/www.scientific.net/MSF.502.249.

[20] P. Kontis, D.M. Collins, A.J. Wilkinson, R.C. Reed, D. Raabe, B. Gault, Microstructural degradation of polycrystalline superalloys from oxidized carbides and implications on crack initiation, Scripta Mater. 147 (2018) 59-63, https:// doi.org/10.1016/j.scriptamat.2017.12.028.

[21] P.R. Bhowal, D. Stolz, A.M. Wusatowska-Sarnek, R. Montero, Surface effects on low cycle fatigue behavior in IN718 alloy, in: Superalloys 2008, Champion (USA), 2008, pp. 417-423, https://doi.org/10.7449/2008/Superalloys_2008_ 417_423.

[22] H. Touazine, M. Jahazi, P. Bocher, Accurate determination of damaged subsurface layers in machined Inconel 718, Int. J. Adv. Manuf. Technol. 88 (2017) 3419-3427, https://doi.org/10.1007/s00170-016-9039-9.

[23] T. Klotz, D. Delbergue, P. Bocher, M. Lévesque, M. Brochu, Surface characteristics and fatigue behavior of shot peened Inconel 718, Int. J. Fatig. 110 (2018) 10-21, https://doi.org/10.1016/j.ijfatigue.2018.01.005.

[24] S. Deyber, F. Alexandre, J. Vaissaud, A. Pineau, Probalistic life of DA718 for aircraft engine disks, in: Superalloys 718, 625, 706 and Various Derivatives vol. 718, 2005, pp. 97-110, https://doi.org/10.7449/2005/Superalloys_2005_ 97_110. Pittsburgh (USA).

[25] D.D. Krueger, S.D. Antolovich, R.H. Van Stone, Effects of grain size and precipitate size on the fatigue crack growth behavior of Alloy 718 at $427{ }^{\circ} \mathrm{C}$ Metall. Trans. A. 18 (1987) 1431-1449, https://doi.org/10.1007/BF02646657.

[26] J.C. Stinville, M.P. Echlin, P.G. Callahan, V.M. Miller, D. Texier, F. Bridier, P. Bocher, T.M. Pollock, Measurement of strain localization resulting from monotonic and cyclic loading at $650 \circ \mathrm{C}$ in nickel base superalloys, Exp. Mech. 57 (2017) 1289-1309, https://doi.org/10.1007/s11340-017-0286-y.

[27] J. Schindelin, I. Arganda-Carreras, E. Frise, V. Kaynig, M. Longair, T. Pietzsch, S. Preibisch, C. Rueden, S. Saalfeld, B. Schmid, J.-Y. Tinevez, D. James White, V. Hartenstein, K. Eliceiri, P. Tomancak, A. Cardona, Fiji: an open-source platform for biological-image analysis, Nat. Methods 9 (2012) 676-682, https://doi.org/10.1016/B978-0-12-415853-5.00046-7.

[28] I.S. Raju, J.C. Newman, Stress-intensity factors for a wide range of semielliptical surface cracks in finite-thickness plates, Eng. Frac. II (1979) 817-829, https://doi.org/10.1016/0013-7944(79)90139-5.

[29] J.-C. Stinville, V.M. Miller, T.M. Pollock, Effect of non-metallic ceramic inclusions on strain localization during low cycle fatigue of a polycrystalline superalloy, in: Superalloys 2016, Champion (USA), 2016, pp. 897-905, https:// doi.org/10.1002/9781119075646.ch96.

[30] W. Hermann, H.G. Sockel, J. Han, A. Bertram, Elastic properties and determination of elastic constants of nickel-base superalloys by a free-free beam technique, in: Superalloys 1996, Champion (USA), 1996, pp. 229-238, https:/ doi.org/10.7449/1996/Superalloys_1996_229_238.

[31] J.O. Kim, J.D. Achenbach, P.B. Mirkarimi, M. Shinn, S.A. Barnett, Elastic constants of single-crystal by line-focus acoustic microscopy nitride films measured, J. Appl. Phys. 72 (1992) 1805-1811, https://doi.org/10.1063/ 1.351651.

[32] N. Rathod, S.D. Gupta, S.K. Gupta, P.K. Jha, First-principles study of structural electronic, elastic, phonon, and thermodynamical properties of the niobium carbide, Solid State Phenom. 171 (2011) 67-77, https://doi.org/10.4028/ www.scientific.net/SSP.171.67.

[33] R. Soundararajan, Behavior of TiN Inclusions and Their Influence in Random Grain Formation in Ni-based Superalloys, PhD Dissertation, The University of British Columbia, 1998

[34] A. Mitchell, S.L. Cockcroft, C.E. Schvezov, A.J. Schmalz, J.N. Loquet, J. Fernihough, Primary carbide and nitride precipitation in superalloys containing niobium, High Temp. Mater. Process. 15 (1996) 27-40, https://doi.org/ 10.1515/HTMP.1996.15.1-2.27.

[35] A. Mitchell, The precipitation of primary carbides in IN718 and its relation to solidification, in: Superalloys 718, 625, 706 and Various Derivatives, 2005. pp. 299-310, https://doi.org/10.7449/2005/Superalloys_2005_299_310. pittsburgh (USA)

[36] M.M. Shenoy, R.S. Kumar, D.L. McDowell, Modeling effects of nonmetallic inclusions on LCF in DS nickel-base superalloys, Int. J. Fatig. 27 (2005) 113-127, https://doi.org/10.1016/j.ijfatigue.2004.06.008.

[37] J. Zhang, R. Prasannavenkatesan, M.M. Shenoy, D.L. McDowell, Modeling fatigue crack nucleation at primary inclusions in carburized and shot-peened martensitic steel, Eng. Fract. Mech. 76 (2009) 315-334, https://doi.org/ 10.1016/j.engfracmech.2008.10.011.

[38] P.S. Karamched, A.J. Wilkinson, High resolution electron back-scatter diffraction analysis of thermally and mechanically induced strains near carbide inclusions in a superalloy, Acta Mater. 59 (2011) 263-272, https://doi.org/ 10.1016/j.actamat.2010.09.030.

[39] H.O. Pierson, Handbook of Refractory Carbides and Nitrides: Properties, Characteristics, Processing and Applications, 1996.

[40] R.E. Pawel, R.K. Williams, Survey of Physical Property Data for Several Alloys, 1985, https://doi.org/10.2172/5337885. ORNL/TM-9616.

[41] R. Prasannavenkatesan, C.P. Przybyla, N. Salajegheh, D.L. McDowell, Simulated extreme value fatigue sensitivity to inclusions and pores in martensitic gear steels, Eng. Fract. Mech. 78 (2011) 1140-1155, https://doi.org/10.1016/ j.engfracmech.2011.01.027.

[42] R. Prasannavenkatesan, J. Zhang, D.L. McDowell, G.B. Olson, H.-J. Jou, 3D modeling of subsurface fatigue crack nucleation potency of primary inclusions in heat treated and shot peened martensitic gear steels, Int. J. Fatig. 31 (2009) 1176-1189, https://doi.org/10.1016/j.ijfatigue.2008.12.001.

[43] W.Z. Abuzaid, M.D. Sangid, J.D. Carroll, H. Sehitoglu, J. Lambros, Slip transfer and plastic strain accumulation across grain boundaries in Hastelloy X, J. Mech. Phys. Solid. 60 (2012) 1201-1220, https://doi.org/10.1016 j.jmps.2012.02.001.

[44] X. Huang, H. Yu, M. Xu, Y. Zhao, Experimental investigation on microcrack initiation process in nickel-based superalloy DAGH4169, Int. J. Fatig. 42 (2012) 153-164, https://doi.org/10.1016/j.ijfatigue.2011.09.003.

[45] J. Jiang, J. Yang, T. Zhang, J. Zou, Y. Wang, F.P.E. Dunne, T.B. Britton, Microstructurally sensitive crack nucleation around inclusions in powder metallurgy nickel-based superalloys, Acta Mater. 117 (2016) 333-344, https:// doi.org/10.1016/j.actamat.2016.07.023.

[46] B. Chen, J. Jiang, F.P.E. Dunne, Is stored energy density the primary meso-scale mechanistic driver for fatigue crack nucleation? Int. J. Plast. 101 (2017) 213-229, https://doi.org/10.1016/j.ijplas.2017.11.005.

[47] J.-C. Stinville, E. Martin, M. Karadge, S. Ismonov, M. Soare, T. Hanlon, S. Sundaram, M.P. Echlin, P.G. Callahan, W.C. Lenthe, J. Miao, A.E. Wessman, R. Finlay, A. Loghin, J. Marte, T.M. Pollock, Competing modes for crack initiation from non-metallic inclusions and intrinsic microstructural features during fatigue in a polycrystalline nickel-based superalloy, Metall. Mater. Trans. A. 49 (2018) 3865-3873, https://doi.org/10.1007/s11661-018-4780-3. 